\title{
Temperature-Regulated Transcription in the Pathogenic Fungus Cryptococcus neoformans
}

\author{
Barbara R. Steen, ${ }^{1}$ Tian Lian, ${ }^{1}$ Scott Zuyderduyn, ${ }^{2}$ William Kim MacDonald, ${ }^{1}$ \\ Marco Marra, ${ }^{2}$ Steven J.M. Jones, ${ }^{2}$ and James W. Kronstad ${ }^{1,3}$ \\ ${ }^{1}$ Biotechnology Laboratory, Department of Microbiology and Immunology, and Faculty of Agricultural Sciences, \\ The University of British Columbia, Vancouver, British Columbia V6T 1Z3, Canada; ${ }^{2}$ Genome Sciences Centre, \\ British Columbia Cancer Research Centre, Vancouver, British Columbia V5Z 4E6, Canada
}

\begin{abstract}
The basidiomycete fungus Cryptococcus neoformans is an opportunistic pathogen of worldwide importance that causes meningitis, leading to death in immunocompromised individuals. Unlike many basidiomycete fungi, $C$. neoformans is thermotolerant, and its ability to grow at $37^{\circ} \mathrm{C}$ is considered to be a virulence factor. We used serial analysis of gene expression (SAGE) to characterize the transcriptomes of $C$. neoformans strains that represent two varieties with different polysaccharide capsule serotypes. These include a serotype $D$ strain of the C. neoformans variety neoformans and a serotype A strain of variety grubii. In this report, we describe the construction and characterization of SAGE libraries from each strain grown at $25^{\circ} \mathrm{C}$ and $37^{\circ} \mathrm{C}$. The SAGE data reveal transcriptome differences between the two strains, even at this early stage of analysis, and identify sets of genes with higher transcript levels at $25^{\circ} \mathrm{C}$ or $37^{\circ} \mathrm{C}$. Notably, growth at the lower temperature increased transcript levels for histone genes, indicating a general influence of temperature on chromatin structure. At $37^{\circ} \mathrm{C}$, we noted elevated transcript levels for several genes encoding heat shock proteins and translation machinery. Some of these genes may play a role in temperature-regulated phenotypes in $C$. neoformans, such as the adaptation of the fungus to growth in the host and the dimorphic transition between budding and filamentous growth. Overall, this work provides the most comprehensive gene expression data available for $C$. neoformans; this information will be a critical resource both for gene discovery and genome annotation in this pathogen.

[This paper is dedicated to the memory of Michael Smith, founding director of the Biotechnology Laboratory and the British Columbia Genome Sciences Centre. The following individuals kindly provided reagents, samples, or unpublished information as indicated in the paper: Brendan Loftus, Claire Fraser, Richard Hyman, Eula Fung, Don Rowley, Ron Davis, Bruce A. Roe, Doris Kupfer, Jennifer Lewis, Sola Yu, Kent Buchanan, Dave Dyer, and Juneann Murphy.]
\end{abstract}

Cryptococcus neoformans has received considerable attention recently because of the high incidence of infections caused by this fungus in immunocompromised individuals (Casadevall and Perfect 1998; Harrison 2000). C. neoformans causes lifethreatening infections in AIDS patients and people receiving immunosuppressive therapy. Cryptococcal meningitis is recognized as an AIDS-related infection, and C. neoformans is also capable of causing disease in immunocompetent individuals (Harrison 2000). Documented virulence factors include the production of a polysaccharide capsule, the formation of melanin, and the ability to grow at $37^{\circ} \mathrm{C}$ (Casadevall and Perfect 1998). Capsule-defective mutants of $C$. neoformans have reduced virulence compared with that of wild-type strains (Chang and Kwon-Chung 1998). Similarly, mutants defective in their ability to produce melanin on media containing phenolic compounds and mutants defective in their ability to grow at $37^{\circ} \mathrm{C}$ also show reduced virulence (Kwon-Chung and Rhodes 1986; Wang et al. 1995; Odom et al. 1997; Nosanchuk et al. 2000). The tolerance of C. neoformans to elevated temperatures has not been explored in detail, although it is

${ }^{3}$ Corresponding author.

E-MAIL kronstad@interchange.ubc.ca; FAX (604) 822-6097.

Article and publication are at http://www.genome.org/cgi/doi/10.1101/ gr.80202. known that mutations in RAS1 and in CNA1 (encoding calcineurin) cause growth defects at elevated temperature (Odom et al. 1997; Alspaugh et al. 2000). There is also an intriguing connection between mating and virulence in C. neoformans; strains of mating-type MAT $\alpha$ have been shown to be more virulent than strains of the MATa mating type, and the majority of clinical isolates are MAT $\alpha$ (Kwon-Chung et al. 1992). One explanation for this prevalence is that only strains of the MAT $\alpha$ mating type form the filamentous cell type that produces the small spores believed to serve as infectious propagules (Wickes et al. 1996).

C. neoformans is a dimorphic fungus that displays a yeast morphology in the haploid phase of the life cycle and a filamentous, dikaryotic cell morphology on mating between compatible haploid strains (Kwon-Chung and Bennett 1992; Casadevall and Perfect 1998). C. neoformans grows primarily by budding during infection, although filamentous growth is sometimes observed in the host (Bemis et al. 2000). Haploid strains of the MAT $\alpha$ mating type can also show filamentous growth in culture in response to nitrogen starvation (Wickes et al. 1996). This filamentous growth (termed haploid fruiting) is associated with the formation of small asexual spores, which may serve as infectious agents via inhalation. Recently, it has been shown that stable diploid strains of $C$. neoformans can be obtained from crosses of compatible haploid mating 
partners (Sia et al. 2000). These diploid strains are thermally dimorphic in that they grow as yeast at $37^{\circ} \mathrm{C}$ and have a filamentous morphology at $24^{\circ} \mathrm{C}$. At the lower temperature, the filaments formed by the diploid strains sporulate to produce haploid, meiotic progeny. Temperature regulation of the morphological switch in C. neoformans is reminiscent of the situation in other fungal pathogens of humans, including Histoplasma capsulatum, Blastomyces dermatitidis, and Paracoccidioides brasiliensis (Medoff et al. 1987; Maresca et al. 1994).

An international consortium has been established to determine the genomic sequence of $C$. neoformans (Heitman et al. 1999b). Initially, the MAT $\alpha$ strain JEC21 was chosen for sequencing because this strain and a congenic MATa isolate (JEC20) have been developed as genetically useful experimental strains (Heitman et al. 1999a). These strains represent the neoformans variety of $C$. neoformans defined in part by the $\mathrm{D}$ serotype of the polysaccharide capsule. In addition, there is considerable interest in obtaining the genomic sequence of other varieties of $C$. neoformans, including the clinical isolate H99 of the serotype A group of C. neoformans (variety grubii). A genomic shotgun sequencing effort is underway at Stanford University and at The Institute for Genomic Research (TIGR) for serotype D strain JEC21 and a related (progenitor) strain, B3501 (Heitman et al. 1999a). Expressed sequence tag (EST) projects for strains JEC21 and H99 are ongoing at the University of Oklahoma's Advanced Center for Genome Technology. In addition, limited shotgun sequencing has been performed for H99 at the Duke University Center for Genome Technology. To contribute to sequencing efforts, we have constructed physical maps of the genomes of strains JEC21 and $\mathrm{H} 99$ by bacterial artificial chromosome (BAC) fingerprinting, and we have performed BAC end sequencing to contribute to assembly of the genomic sequences (J. Schein et al. 2002).

In this report, we describe the use of serial analysis of gene expression (SAGE) to examine the transcriptome of $C$. neoformans as a function of temperature. SAGE involves generating short sequence (nine to $13 \mathrm{bp}$ ) tags that represent individual transcripts and using large-scale sequencing to establish the frequency of occurrence of these tags as a measure of transcript levels (Velculescu et al. 1995). SAGE has been used to define the transcriptome for Saccharomyces cerevisiae (Velculescu et al. 1997) and to explore transcription in normal and tumor cells (see Zhang et al. 1997). We chose SAGE instead of microarrays for defining the C. neoformans transcriptome because the small collections of available ESTs precluded the use of microarrays. In addition, SAGE data are digital and provide the opportunity for robust statistical analysis (Audic

Table 1. Analysis of SAGE libraries

\begin{tabular}{|c|c|c|c|c|}
\hline & \multicolumn{2}{|c|}{ H99 } & \multicolumn{2}{|c|}{ B3501 } \\
\hline & $25^{\circ} \mathrm{C}$ & $37^{\circ} \mathrm{C}$ & $25^{\circ} \mathrm{C}$ & $37^{\circ} \mathrm{C}$ \\
\hline Sequence reads & 1815 & 2213 & 4126 & 2165 \\
\hline Total tags* & 30,181 & 37,467 & 65,399 & 15,363 \\
\hline \multicolumn{5}{|l|}{ Tag families } \\
\hline Singletons & 4406 (14.1\%) & $4196(10.6 \%)$ & 5967 (8.8\%) & 3693 (23.8\%) \\
\hline 2 to 10 & $2703(8.7 \%)$ & $2821(6.9 \%)$ & $4468(6.6 \%)$ & 2029 (13.0\%) \\
\hline 11 to 100 & $441(1.4 \%)$ & $564(1.4 \%)$ & $1082(1.6 \%)$ & $201(1.3 \%)$ \\
\hline$>100$ & $25(0.09 \%)$ & $43(0.13 \%)$ & $65(0.11 \%)$ & $3(0.02 \%)$ \\
\hline Total & 7575 & 7624 & 11,582 & 5926 \\
\hline
\end{tabular}

*Ninety-nine percent probability that each tag sequence is correct. and Claverie 1997). Furthermore, when used in conjunction with genomic sequence data, SAGE results have been useful in all stages of genome annotation and, in particular, for gene identification (see Jones et al. 2001). Our experiments show the utility of SAGE for the genome-wide analysis of transcription in fungi and represent the first application of this technique to a human pathogen. Our SAGE analysis for $C$. neoformans revealed substantial differences in the transcriptomes of different serotypes and allowed the identification of sets of genes whose transcript levels vary with temperature. The characterization of the latter genes provides insight into the ability of $C$. neoformans to grow at $37^{\circ} \mathrm{C}$ in the human host.

\section{RESULTS AND DISCUSSION}

\section{Temperature Regulation of Transcript Levels in C. neoformans}

Four SAGE libraries were constructed and sequenced to generate RNA expression data for C. neoformans strains B3501 and $\mathrm{H} 99$, each grown at $25^{\circ} \mathrm{C}$ and $37^{\circ} \mathrm{C}$. A summary of the collection of tags for each library is presented in Table 1 . The collection and processing of the tag data included the use of Phred scores for the sequence traces to establish a statistical level of confidence in the sequence of each tag (see Methods). The data shown in Table 1 reflect Phred scores that provide a $99 \%$ probability that each tag sequence is correct. The collection of SAGE tags at two different temperatures provided a means to assess genome-wide changes in expression for two strains. Figure 1 presents the expression profile at the two temperatures for the serotype A strain H99. Of 12,056 tag species analyzed, $12.5 \%$ (1507 tag species) showed a significant difference $(P \leq 0.05)$ between the two temperatures. A tag species is defined as the unique sequence identifier of a particular tag. Figure 2 presents the expression profile at the two temperatures for the serotype D strain B3501. For this strain, a total of 13,615 tag species were analyzed, and 4.9\% (664 tag species) showed a significant difference $(P \leq 0.05)$ between the two temperatures. For comparison, a recent analysis of the influence of temperature on global gene expression in group A Streptococcus revealed that $9 \%$ of the genes were differentially transcribed at $29^{\circ} \mathrm{C}$ versus $37^{\circ} \mathrm{C}$ (Smoot et al. 2001).

\section{Identification of Genes for the Most Highly Expressed Tags for the Serotype A and D Strains}

Although an annotated genomic sequence is not available for any strain of $C$. neoformans, we were able to make preliminary tag assignments to specific predicted genes with the partial genomic and EST sequence data for both strains. For strain H99, we have made preliminary gene assignments for 19 and 29 of the top 50 most abundant tags from the $25^{\circ} \mathrm{C}$ and $37^{\circ} \mathrm{C}$ libraries, respectively (Table 2A,B). In this strain, 20 tags were found to be identical in the top 50 of both libraries. A total of 70 unique tag species were studied, and 42 of these were associated with an EST sequence; 38 of the EST sequences gave significant BLASTP results, leading to putative gene assignments. Within the top 50 tags, 


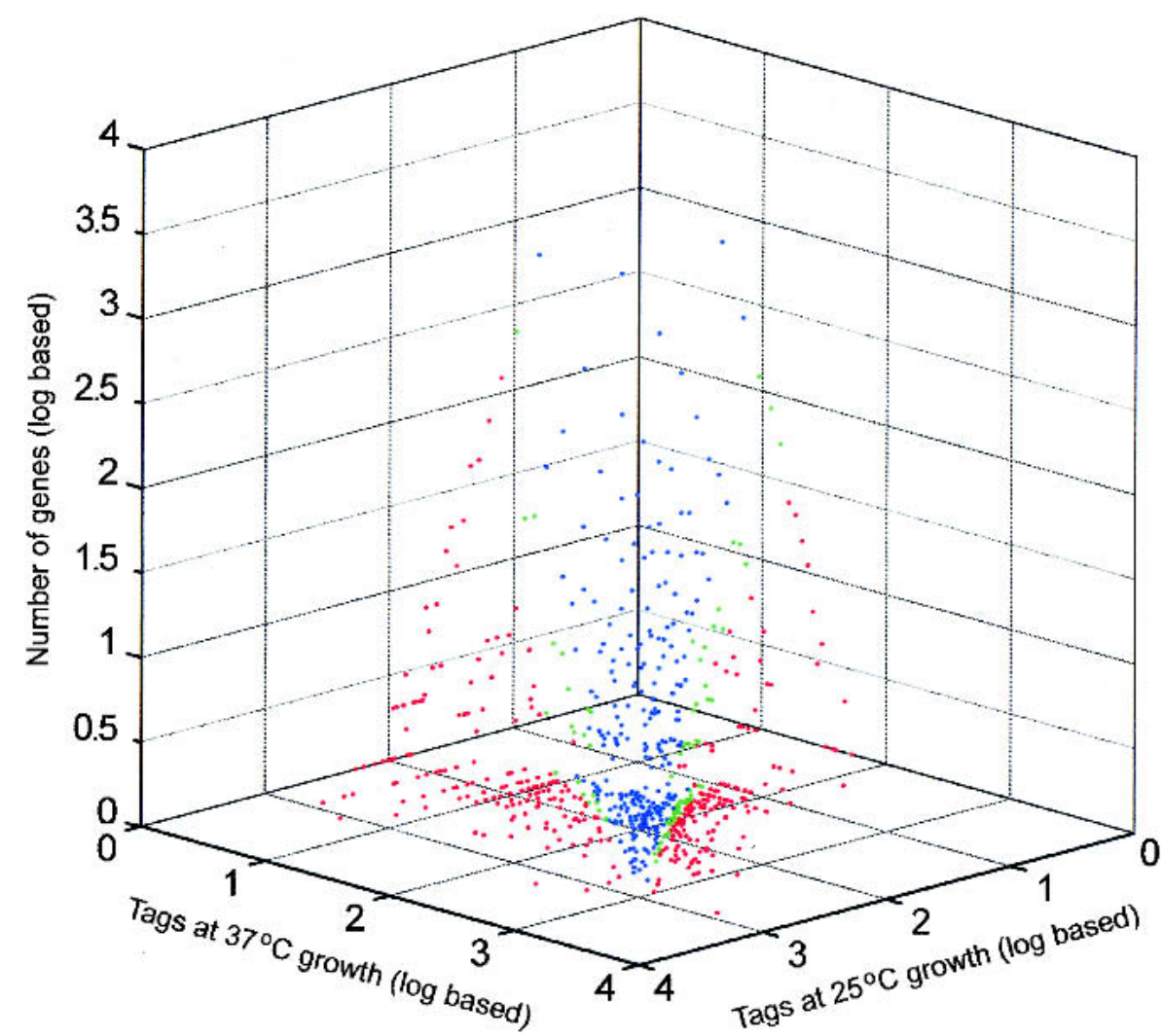

Figure 1 Expression profile comparing relative transcript levels at $25^{\circ} \mathrm{C}$ and $37^{\circ} \mathrm{C}$ in strain $\mathrm{H} 99$. Singleton tags were excluded. Blue dots indicate tags that do not show a significant expression difference; green dots, tags with a difference that is significant at $95 \%$ to $99 \%$ confidence; and red dots, tags with a significance of $>99 \%$ confidence.

we identified genes for three ribosomal proteins at $25^{\circ} \mathrm{C}$ and 12 ribosomal proteins at $37^{\circ} \mathrm{C}$. Furthermore, the top 50 tags (for both libraries) identified genes for proteins that are generally considered to be abundant in other organisms. These include GAPDH, translation elongation factor, pyruvate decarboxylase, malate dehydrogenase, and fructosebisphosphate aldolase. Interestingly, a tag representing the transcript of a zinc transport protein was the most highly expressed tag at $25^{\circ} \mathrm{C}$ but was not seen in the top 50 tags for the $37^{\circ} \mathrm{C}$ library. As well, the tag representing cyclophilin A (CPA1 and CPA2) was identified in the top 50 of both libraries but was expressed 1.47 times higher at $37^{\circ} \mathrm{C}$. The genes encoding cyclophilin A have been characterized in $C$. neoformans, and Cpa1 is required for growth at elevated temperature and for virulence (Wang et al. 2001). Two of the abundant tags at $37^{\circ} \mathrm{C}$ identified transcripts for a thioredoxin peroxidase $(0.74 \%)$ and a superoxide dismutase $(0.35 \%)$. These tags were approximately fourfold higher at $37^{\circ} \mathrm{C}$ relative to $25^{\circ} \mathrm{C}$. Lee and Park (1998) have shown that a thioredoxin peroxidase contributes to thermotolerance in S. cerevisiae, presumably by acting as an antioxidant. Superoxide dismutase plays a wellcharacterized role in antioxidant defense, and the production of the enzyme is known to be higher at $37^{\circ} \mathrm{C}$ than at $25^{\circ} \mathrm{C}$ in $\mathrm{C}$. neoformans (Jacobson et al. 1994). The expression of this protein is also known to be influenced by temperature in other pathogens such as group A Streptococcus (Smoot et al. 2001). In general, these results indicate that growth at $37^{\circ} \mathrm{C}$ may induce the expression of genes involved in a stress response in C. neoformans.
The availability of more genomic sequence information for the serotype D strains JEC21 and B3501 (relative to strain H99) allowed us to make preliminary gene assignments for 33 and 34 of the top 50 most abundant tags prepared with cells grown at $25^{\circ} \mathrm{C}$ and $37^{\circ} \mathrm{C}$, respectively (Table $\left.3 \mathrm{~A}, \mathrm{~B}\right)$. In this strain, substantially more tags (33) were found to be identical in the top 50 of both libraries compared with the H99 libraries. This finding is consistent with the lower percentage of differentially expressed genes for B3501 (Fig. 2). In total, 141 unique tag species were studied for strain B3501, 75 of which were given putative gene assignments based on a significant BLASTP result. Only eight tags did not associate with an EST or a genomic sequence contig. Of those tags that did not result in a putative gene assignment, 20 tags were ambiguous because they hit more than one sequence contig.

As in the H99 libraries, the top 50 tags represented genes for four $\left(25^{\circ} \mathrm{C}\right)$ and $11\left(37^{\circ} \mathrm{C}\right)$ ribosomal proteins, as well as genes for proteins that are expected to be abundant such as translation elongation factor, pyruvate decarboxylase, and GAPDH. The tag for the cyclophilin A transcript was seen at both $25^{\circ} \mathrm{C}$ and $37^{\circ} \mathrm{C}$ for $\mathrm{B} 3501$, although the tag was differentially expressed in an opposite manner (approximately twofold higher at $25^{\circ} \mathrm{C}$ in $\mathrm{B} 3501$ ) compared with the results for the $\mathrm{H} 99$ libraries. Also in contrast to the H99 libraries, the 50 most abundant tags in both B3501 libraries did not include a tag representing fructose-bisphosphate aldolase. For B3501, the list of abundant tags also revealed high transcript levels for the genes predicted to encode a ubiquitin RPS27A fusion protein, a ubiquitin conjugating enzyme, an iron permease, and a serine-threonine protein kinase that may be involved in pre-mRNA splicing (similar to Prp4p of Schizosaccharomyces pombe; Schwelnus et al. 2001). These genes were not identified in the top 50 tags from the $\mathrm{H} 99$ libraries at either temperature. In addition, the most abundantly expressed genes from both the $25^{\circ} \mathrm{C}$ and $37^{\circ} \mathrm{C}$ libraries of $\mathrm{B} 3501$ contained a zinc transporter that was seen only in the $25^{\circ} \mathrm{C}$ library from $\mathrm{H} 99$.

The $\mathrm{B} 350137^{\circ} \mathrm{C}$ library revealed tags representing several proteins not seen in the $25^{\circ} \mathrm{C}$ library. These included the ER chaperone $\mathrm{BiP}$ (approximately twofold higher at $37^{\circ} \mathrm{C}$ ), a peripheral benzodiazepine receptor homolog (discussed below), and several ribosomal proteins. Interestingly, the thioredoxin peroxidase tag that was found only in the top 50 tags of the $37^{\circ} \mathrm{C}$ library from $\mathrm{H} 99$ was identified in both the $25^{\circ} \mathrm{C}$ and $37^{\circ} \mathrm{C}$ top 50 tags of strain B3501. Overall, these results indicate that there are several differences in the response of H99 and B3501 to elevated temperature. A more extensive comparison will be possible when more tags can be matched with genes on completion and annotation of the genomic sequences of both strains. 


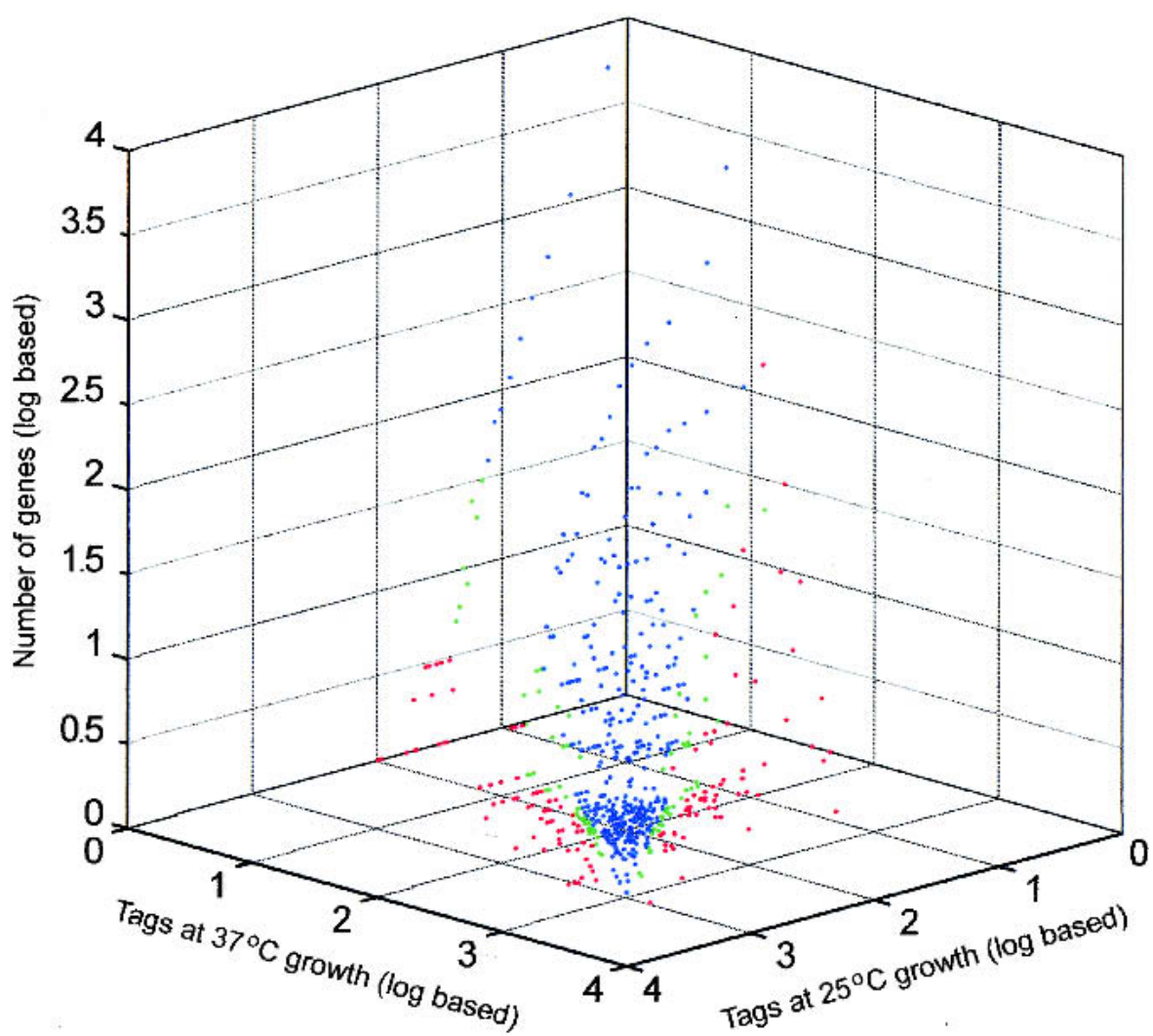

Figure 2 Expression profile comparing relative transcript levels at $25^{\circ} \mathrm{C}$ and $37^{\circ} \mathrm{C}$ in strain $\mathrm{B} 3501$. Singleton tags were excluded. Blue dots indicate tags that do not show a significant expression difference; green dots, tags with a difference that is significant at $95 \%$ to $99 \%$ confidence; and red dots, tags with a significance of $>99 \%$ confidence.

The SAGE analysis of the most highly expressed genes in C. neoformans is comparable to that of $S$. cerevisiae (Velculescu et al. 1997). In yeast, the proteins encoded by the top 30 highly expressed genes included GAPDH, translation elongation factor- $\alpha$, alcohol dehydrogenase, fructosebisphosphate aldolase, pyruvate decarboxylase, and 18 ribosomal proteins. On the other hand, a comparison of our results with the changes in transcript levels observed for $S$. cerevisiae genes at $25^{\circ} \mathrm{C}$ and $37^{\circ} \mathrm{C}$ (as measured by microarray analysis; Gasch et al. 2000) indicates that temperature influences the transcription of a relatively greater number of genes in C. neoformans.

\section{Tags With Higher Levels at $25^{\circ} \mathrm{C}$}

To begin to determine differences in transcript levels at the two temperatures, we made preliminary gene assignments for a selected group of 100 tags that showed the most statistically significant different expression levels between the two temperatures. All of these tags have a value of $P<0.05$ as the minimum level of significance for concluding that a given tag showed differential expression. The fold difference for the tag levels was determined by normalizing the total tag numbers to represent libraries of equal sizes. We note that the calculation of fold-difference is less accurate in this analysis when the number of tags is small, although the $P$ value calculation is unaffected. We focused our analysis on the data for strain B3501 because, as noted earlier, there is substantially more genomic sequence information available for this strain compared with H99.

The analysis of 50 tags with higher levels at $25^{\circ} \mathrm{C}$ revealed several patterns of transcription that may reflect general features of temperature adaptation in $C$. neoformans (Table 4). First, the tags representing transcripts for histones $\mathrm{H} 1$, $\mathrm{H} 3$, and $\mathrm{H} 4$ were all elevated at $25^{\circ} \mathrm{C}$ compared with $37^{\circ} \mathrm{C}$ (approximately two- to sevenfold). Assuming that these changes in transcript levels reflect changes in the abundance of histone proteins, our results indicate that growth temperature may exert a general influence on chromatin structure in C. neoformans. This was corroborated by the fact that at $37^{\circ} \mathrm{C} \mathrm{H} 4$ was expressed 10 -fold more than $\mathrm{H} 1$, whereas at $25^{\circ} \mathrm{C}, \mathrm{H} 4$ was expressed only threefold more than H1. These observations indicate that growth temperature causes a change in the relative expression of histone gene families. In turn, this may reflect a broad shift in gene expression for this pathogen as a function of temperature. This conclusion is supported by results from $S$. cerevisiae in which the examination of changes in histone abundance (e.g., by depletion of histone $\mathrm{H} 4$ ) revealed changes in the expression of $\sim 25 \%$ of all of the genes (Wyrick et al. 1999).

A second notable group of tags that were up-regulated at $25^{\circ} \mathrm{C}$ represented genes for sterol and lipid metabolism. The expression pattern for these genes is consistent with observations in other organisms in which adjustments in membrane composition are correlated with growth temperature (Steels et al. 1994; Los et al. 1997; Aguilar et al. 1998). In general, cells adapt to a lower temperature by an increase in the production of desaturase, resulting in unsaturated fatty acids in membrane phospholipids to maintain proper fluidity. That is, we would expect the SAGE data to reveal changes in transcript levels for desaturase genes as a function of temperature, and we did identify a tag for the transcript of a $\Delta 9$ fatty acid desaturase that was elevated 14.56 -fold at $25^{\circ} \mathrm{C}$. Other tags that were elevated at $25^{\circ} \mathrm{C}$ included those representing genes for sterol synthesis (sterol C-5 desaturase and C-4 methyl sterol oxidase) and fatty acid synthesis (fatty acid synthases). Sterol content in C. neoformans is known to change in response to passage of the fungus through an animal host (Currie et al. 1995). Changes in membrane composition have also been correlated with morphogenesis and thermotolerance in other fungal pathogens. For example, a $\Delta 9$ fatty acid desaturase is regulated by temperature and cAMP signaling during the dimorphic transition in Histoplasma capsulatum (Storlazzi et al. 1999). These observations may be relevant for C. neoformans because signaling via a cAMP pathway is known to play an important role in the virulence (Alspaugh et al. 1997, 2001; D'Souza et al. 2001). 
Table 2A. Top 50 Tags Expressed at $25^{\circ} \mathrm{C}$ for Strain $\mathrm{H} 99$

\begin{tabular}{|c|c|c|c|c|c|}
\hline SAGE tag & $\begin{array}{c}\text { Frequency } \\
(30,181 \text { total })\end{array}$ & $\%$ Abundance & $\begin{array}{l}\text { Prelimary gene } \\
\text { designation }\end{array}$ & $\begin{array}{l}\text { E-value of } \\
\text { BLASTx }\end{array}$ & $\begin{array}{l}\text { Accession no. } \\
\text { of BLASTx }\end{array}$ \\
\hline ttcagcaggc & 430 & $1.42 \%$ & Zinc transport protein & $7.00 \mathrm{E}-15$ & $\begin{array}{l}\text { Saccharomyces cerevisiae } \\
\text { Z72777 }\end{array}$ \\
\hline ctcagcgatg & 352 & $1.17 \%$ & NO HIT & & \\
\hline cattcgcata & 309 & $1.02 \%$ & NO HIT ${ }^{a}$ & & \\
\hline cgacagaccg & 222 & $0.74 \%$ & Translation elongation factor $1 \alpha$ & $0.00 \mathrm{E}+00$ & $\begin{array}{l}\text { Cryptococcus neoformans } \\
\text { U81804 }\end{array}$ \\
\hline aаaaaaaaaa & 211 & $0.70 \%$ & $\mathrm{NO} \mathrm{HIT} \mathrm{T}^{\mathrm{a}}$ & & \\
\hline atatgacata & 210 & $0.70 \%$ & $\mathrm{NOHIT}$ & & \\
\hline gccaacgecg & 203 & $0.67 \%$ & Cyclophilin A & $2 \mathrm{E}-72^{\mathrm{c}}$ & C. neoformans U81804 \\
\hline getctccagg & 171 & $0.57 \%$ & NO HIT & & \\
\hline catctgttcc & 171 & $0.57 \%$ & $\mathrm{NOHIT}$ & & \\
\hline cgcggaaagg & 162 & $0.54 \%$ & NO HIT ${ }^{a}$ & & \\
\hline tagcgatcac & 153 & $0.51 \%$ & NO HITa & & \\
\hline tagccgcgaa & 153 & $0.51 \%$ & NO HIT & & \\
\hline ataagctttc & 148 & $0.49 \%$ & Mannitol 1-phosphate dehydrogenase & $3.00 \mathrm{E}-18$ & C. neoformans AF175685 \\
\hline gtttccgctg & 147 & $0.49 \%$ & NO HIT & & \\
\hline ttcggcaagg & 132 & $0.44 \%$ & ADP, ATP carrier protein & $1.40 \mathrm{E}-131$ & Neurospora crassa X00363 \\
\hline gtcggtggta & 130 & $0.43 \%$ & ATP synthase $\beta$-chain & $8.00 \mathrm{E}-59$ & Kluyveromyces lactis U37764 \\
\hline gtggacacga & 129 & $0.43 \%$ & Nucleoside diphosphate-sugar hydrolase & 4.00E-26 & S. cerevisiae CAA85068 \\
\hline aatgaatctt & 122 & $0.40 \%$ & $\mathrm{NO} \mathrm{HIT}{ }^{\mathrm{a}}$ & & \\
\hline tctggtcgag & 121 & $0.40 \%$ & Histone $\mathrm{H} 4$ & $2.90 \mathrm{E}-36$ & Agaris bisporus P35058 \\
\hline tcagaagttg & 121 & $0.40 \%$ & Thioredoxin & $9.00 \mathrm{E}-25$ & Coprinus comatus AJ242791 \\
\hline agcgagcact & 120 & $0.40 \%$ & NO HIT ${ }^{\mathrm{a}}$ & & \\
\hline gtattgaccc & 113 & $0.37 \%$ & Hypothetical protein & $4 \mathrm{E}-69^{c}$ & $\begin{array}{l}\text { Streptomyces coelicolor } \\
\text { AL132991 }\end{array}$ \\
\hline atgatcgggc & 108 & $0.36 \%$ & $\mathrm{NOHIT}$ & & \\
\hline aaaacgcgt & 107 & $0.35 \%$ & Myo-inositol-1-phosphate synthase & $1.00 \mathrm{E}-66$ & $\begin{array}{l}\text { Drosophila melanogaster } \\
\text { AF071103 }\end{array}$ \\
\hline catcactctt & 103 & $0.34 \%$ & Pyruvate decarboxylase & $8.0 \mathrm{E}-34^{\mathrm{c}}$ & $\begin{array}{l}\text { Saccharomyces kluyveri } \\
\text { AF193853 }\end{array}$ \\
\hline ccgcgaccgt & 98 & $0.32 \%$ & $\mathrm{NO} \mathrm{HIT} \mathrm{T}^{\mathrm{a}}$ & & \\
\hline getgcctaca & 93 & $0.31 \%$ & ATP synthase $-\gamma$-chain & $5.00 \mathrm{E}-21$ & N. crassa AL355930 \\
\hline acggtggcaa & 92 & $0.30 \%$ & $\mathrm{NO} \mathrm{HIT} \mathrm{T}^{\mathrm{a}}$ & & \\
\hline acacgtctgg & 91 & $0.30 \%$ & $\mathrm{NO} \mathrm{HIT} \mathrm{T}^{\mathrm{a}}$ & & \\
\hline ggttacgccg & 91 & $0.30 \%$ & Malate dehydrogenase & $2.00 \mathrm{E}-35$ & S. cerevisiae 02841 \\
\hline gcgttctcgg & 86 & $0.28 \%$ & Transaldolase & $1.00 \mathrm{E}-102$ & $\begin{array}{l}\text { Schizosaccharomyces pombe } \\
\text { AL023518 }\end{array}$ \\
\hline actcaggttg & 83 & $0.28 \%$ & Fructose 1,6-bisphosphate aldolase & $2.00 \mathrm{E}-46$ & N. crassa $L 42380$ \\
\hline gaatagtggg & 81 & $0.27 \%$ & NO HIT ${ }^{a}$ & & \\
\hline ggccgacctg & 80 & $0.27 \%$ & 605 ribosomal protein RPL11 & $3.00 \mathrm{E}-81$ & S. pombe Z69240 \\
\hline atgcatttcg & 80 & $0.27 \%$ & NO HIT ${ }^{a}$ & & \\
\hline getcgcgacg & 77 & $0.26 \%$ & $60 S$ ribosomal protein RPL2 & $1.00 \mathrm{E}-103$ & Xenopus laevis U00920 \\
\hline atatgtatcg & 75 & $0.25 \%$ & NO HIT ${ }^{a}$ & & \\
\hline aacgtctgcc & 74 & $0.25 \%$ & $\mathrm{NO} \mathrm{HIT}$ & & \\
\hline accgtcgttg & 74 & $0.25 \%$ & NO HIT ${ }^{a}$ & & \\
\hline tgcaaacgcg & 74 & $0.25 \%$ & Peroxisomal membrane protein & $6.00 \mathrm{E}-12$ & S. pombe AJ002536 \\
\hline gegcegctta & 72 & $0.24 \%$ & $\mathrm{NOHIT} \mathrm{H}^{\mathrm{a}}$ & & \\
\hline aagcgcatttt & 71 & $0.24 \%$ & $\mathrm{NO} \mathrm{HIT}^{\mathrm{a}}$ & & \\
\hline tagtgtcccg & 70 & $0.23 \%$ & $\mathrm{NO} \mathrm{HIT}{ }^{\mathrm{a}}$ & & \\
\hline aagggtggtg & 68 & $0.23 \%$ & NO HIT & & \\
\hline aagcctgacg & 67 & $0.22 \%$ & NO HIT & & \\
\hline aatggtttg & 66 & $0.22 \%$ & NO HIT & & \\
\hline catcacgctt & 64 & $0.21 \%$ & 60s ribosomal protein RPL5 & $3.00 \mathrm{E}-26$ & S. pombe AL031528 \\
\hline agcaaggagg & 63 & $0.21 \%$ & NO HIT ${ }^{a}$ & & \\
\hline taacgcataa & 63 & $0.21 \%$ & NO HIT & & \\
\hline agcaaggagg & 63 & $0.21 \%$ & $\mathrm{NO} \mathrm{HIT}{ }^{\mathrm{a}}$ & & \\
\hline
\end{tabular}

aSerial analysis of gene expression (SAGE) tag does not have an associated expressed sequence tag (EST) at http://www.genome.ou.edu/ cneo.html.

bIdentified EST does not have a significant BLASTx result at http://www.ncbi.nlm.nih.gov/.

'BLASTx results for a contig identified at http://mgm.duke.edu.

An additional general observation for the tags with higher levels at $25^{\circ} \mathrm{C}$ is that many represent genes for transport functions. These included a gene involved in iron transport, as well as glucose and inositol transporters. Inositol metabolism has been examined in C. neoformans and is proposed to be important for pathogenesis (Luberto et al. 2001). This may be relevant for virulence because of the preference of $C$. neoformans for growth in the central nervous system, a location known to be rich in inositol (Vincent and Klig 1995). We also found that the tag for a putative 
Table 2B. Top 50 Tags Expressed at $37^{\circ} \mathrm{C}$ for Strain $\mathrm{H} 99$

\begin{tabular}{|c|c|c|c|c|c|}
\hline SAGE tag & $\begin{array}{c}\text { Frequency } \\
(37,467 \text { total })\end{array}$ & $\%$ Abundance & EST hit & E-value & $\begin{array}{l}\text { Accession no. } \\
\text { of BLASTx }\end{array}$ \\
\hline cgacagaccg & 931 & $2.48 \%$ & Translation elongation factor $1 \alpha$ & $0.00 \mathrm{E}+00$ & C. neoformans U81804 \\
\hline ggcetcggtt & 387 & $1.03 \%$ & NO HITS ${ }^{a}$ & & \\
\hline tcccegtaca & 330 & $0.88 \%$ & NO HITS ${ }^{a}$ & & \\
\hline gccaacgecg & 300 & $0.80 \%$ & Cyclophilin A & $2 \mathrm{E}-72^{\mathrm{c}}$ & C. neoformans U81804 \\
\hline cacgttcacg & 276 & $0.74 \%$ & Thioredoxin peroxidase & $9.00 \mathrm{E}-64$ & S. pombe AL031798 \\
\hline aacgtctgcc & 272 & $0.73 \%$ & NO HITS ${ }^{a}$ & & \\
\hline cgcggaaagg & 264 & $0.70 \%$ & NO HITS ${ }^{a}$ & & \\
\hline getcgcgacg & 259 & $0.69 \%$ & 60 S ribosomal protein $\mathrm{RPL2}$ & $1 \mathrm{E}-103$ & X. laevis U00920 \\
\hline ggccgacctg & 256 & $0.68 \%$ & 60 S ribosomal protein RPL11 & $3 \mathrm{E}-81$ & S. pombe Z69240 \\
\hline gtcggtggta & 228 & $0.61 \%$ & ATP synthase $\beta$-chain & $8 \mathrm{E}-59$ & Kluyveromyces lactis U37764 \\
\hline gtttccgctg & 223 & $0.60 \%$ & NO HITS ${ }^{a}$ & & \\
\hline aagggtggtg & 204 & $0.54 \%$ & NO HITS ${ }^{a}$ & & \\
\hline aagcccgttg & 194 & $0.52 \%$ & NO HITS & & \\
\hline tctgtcgagg & 183 & $0.49 \%$ & 40S ribosomal protein RPS12 & $3 E-41$ & Susscrofa X79417 \\
\hline gagaagcgtg & 174 & $0.46 \%$ & $60 S$ ribosomal protein RPL21A & $4.10 \mathrm{E}-51$ & S. cerevisiae M86408 \\
\hline ctcagcgatg & 173 & $0.46 \%$ & NO HITS ${ }^{b}$ & & \\
\hline cacggcgcat & 164 & $0.44 \%$ & $60 S$ ribosomal protein RPL41 & $2.00 \mathrm{E}-58$ & $\begin{array}{l}\text { Xanthophyllomyces dendrorhous } \\
\text { AF004672 }\end{array}$ \\
\hline taggccgtct & 158 & $0.42 \%$ & NO HITS ${ }^{a}$ & & \\
\hline aaggactctc & 158 & $0.42 \%$ & 40S ribosomal protein RPS15 & $2.60 \mathrm{E}-42$ & Podospora anserina Z23267 \\
\hline getctccagg & 155 & $0.41 \%$ & NO HITS ${ }^{a}$ & & \\
\hline tctggtcgag & 152 & $0.41 \%$ & Histone $\mathrm{H} 4$ & $2.9 \mathrm{E}-36$ & Agaris bisporus P35058 \\
\hline tccetattaa & 151 & $0.40 \%$ & NO HITS ${ }^{a}$ & & \\
\hline cagaaccccg & 147 & $0.39 \%$ & 40s ribosomal protein RPS18 & $6.9 \mathrm{E}+45$ & S. pombe AL034564 \\
\hline acggecgtta & 139 & $0.37 \%$ & NO HITS ${ }^{a}$ & & \\
\hline aaaaaaaaaa & 135 & $0.36 \%$ & NO HITS ${ }^{a}$ & & \\
\hline ctcttcccet & 135 & $0.36 \%$ & $60 S$ ribosomal protein RPL33B & $9 \mathrm{E}-31$ & S. cerevisiae L23923 \\
\hline tctttccgag & 135 & $0.36 \%$ & GAPDH & $2.80 \mathrm{E}-59$ & C. neoformans AF106950 \\
\hline gtattgaccc & 131 & $0.35 \%$ & Hypothetical protein & 4.0E-69 & Streptomyces coelicolor AL132991 \\
\hline cacgtccacg & 131 & $0.35 \%$ & $\mathrm{Cu}, \mathrm{Zn}$ superoxide dismutase & $5.5 \mathrm{E}-51$ & Aspergillus fumigatus AF128886 \\
\hline getgcctaca & 130 & $0.35 \%$ & ATP synthase $-\gamma$-chain & $2.00 \mathrm{E}-33$ & N. crassa AL355930 \\
\hline gecgtccgaa & 130 & $0.35 \%$ & $40 S$ ribosomal protein RPS5 & 4.40E-71 & Mus musculu U78085 \\
\hline getcetcta & 128 & $0.34 \%$ & ATP synthase $\alpha$-chain & $1.90 \mathrm{E}-01$ & N. crassa M84191 \\
\hline tctttgatgt & 125 & $0.33 \%$ & ADP, ATP carrier protein & $1.4 \mathrm{E}-122$ & N. crassa $\times 00363$ \\
\hline tccatccgat & 123 & $0.33 \%$ & 60 S ribosomal protein RPL10 & $8.90 \mathrm{E}-83$ & S. cerevisiae U06952 \\
\hline atgatcgggc & 123 & $0.33 \%$ & NO HITS ${ }^{a}$ & & \\
\hline getttgctgc & 122 & $0.33 \%$ & $\begin{array}{l}\text { Hypothetical protein } \\
\text { (Schizosaccharomyces pombe) }\end{array}$ & $1.80 \mathrm{E}-11$ & S. pombe Z97992 \\
\hline atgggetccc & 119 & $0.32 \%$ & ATP synthase $-\gamma$-chain & $2.9 \mathrm{E}-30$ & S. pombe AL031856 \\
\hline gacgactcta & 116 & $0.31 \%$ & NO HITS ${ }^{a}$ & & \\
\hline gagttgttga & 115 & $0.31 \%$ & 60 S ribosomal protein RPL36 & $3.6 \mathrm{E}-13$ & S. pombe D88771 \\
\hline actcaggttg & 114 & $0.30 \%$ & Fructose 1,6-bisphosphate aldolase & $2.0 \mathrm{E}-46^{\mathrm{c}}$ & Aspergillus oryzae $\mathrm{AB} 032272$ \\
\hline ccgegaccgt & 113 & $0.30 \%$ & NO HITS ${ }^{a}$ & & \\
\hline gettttgcec & 110 & $0.29 \%$ & NO HITS ${ }^{a}$ & & \\
\hline ttcggcaagg & 107 & $0.29 \%$ & ADP, ATP carrier protein & $1.4 \mathrm{E}-131$ & N. crassa $\times 00363$ \\
\hline tcggtcgtgt & 104 & $0.28 \%$ & Suppressor protein STM1 & 0.05 & S. cerevisiae D26183 \\
\hline cctcttcctg & 102 & $0.27 \%$ & NO HITS ${ }^{a}$ & & \\
\hline ggttacgecg & 98 & $0.26 \%$ & Malate dehydrogenase & $2 \mathrm{E}-35$ & S. cerevisiae Z28085 \\
\hline gcgttctcgg & 95 & $0.25 \%$ & Transaldolase & $3.30 \mathrm{E}-102$ & S. pombe AL023518 \\
\hline cgtgtcaagc & 95 & $0.25 \%$ & NO HITS ${ }^{a}$ & & \\
\hline gtcaagaagc & 95 & $0.25 \%$ & NO HITS ${ }^{a}$ & & \\
\hline ggtatcctcg & 95 & $0.25 \%$ & Putative $40 \mathrm{~S}$ ribosomal protein & $5 \mathrm{E}-50$ & S. pombe NC_003424 \\
\hline
\end{tabular}

aSerial analysis of gene expression (SAGE) tag does not have an associated expressed sequence tag (EST) at http://www.genome.ou.edu/ cneo.html.

bIdentified EST does not have a significant BLASTx result at http://www.ncbi.nlm.nih.gov/.

'BLASTx results for a contig identified at http://mgm.duke.edu

inositol synthase gene was up-regulated at $25^{\circ} \mathrm{C}$, further indicating a connection between inositol metabolism and growth temperature.

In addition to our analysis of 50 differentially expressed tags (Table 4), we also found that the tag for a C. neoformans translation elongation factor-3 (TEF3; ATGTATATAC) was 6.10-fold more abundant at $25^{\circ} \mathrm{C}$. TEF3 is a fungal-specific elongation factor, and transcript levels for this gene are known to change in C. albicans as a function of temperature. That is, changes in transcript levels have been observed during growth at different temperatures, although these changes do not seem to be associated with temperature-regulated dimorphism in this fungus. As well, there is evidence to support the idea that reduced transcription of TEF3 in C. albicans results in decreased virulence in a mouse model of infection (Nakayama et al. 2000). 
Table 3A. Top 50 Tags Expressed at $25^{\circ} \mathrm{C}$ for Strain B3501

\begin{tabular}{|c|c|c|c|c|c|}
\hline SAGE tag & $\begin{array}{c}\text { Frequency } \\
(65,399 \\
\text { total })\end{array}$ & Percentage & $\begin{array}{l}\text { Preliminary gene } \\
\text { designation }\end{array}$ & $\begin{array}{l}\text { E-value of top } \\
\text { BLASTx result }\end{array}$ & $\begin{array}{l}\text { Accession no. } \\
\text { of BLASTx }\end{array}$ \\
\hline gaacgatgct & 607 & $0.93 \%$ & NO HITS & & \\
\hline catttacata & 546 & $0.83 \%$ & NO HITS & & \\
\hline cgagtcgtat & 539 & $0.82 \%$ & Iron permease & $2 \mathrm{E}-23$ & $\begin{array}{l}\text { Schizosaccharomyces pombe } \\
\text { Z67998 }\end{array}$ \\
\hline cgacagaccg & 529 & $0.81 \%$ & Translation elongation factor 1 & $0.0 / 0.0^{c}$ & $\begin{array}{l}\text { Cryptococcus neoformans } \\
\text { U81804 }\end{array}$ \\
\hline aaaaaaaaa & 452 & $0.69 \%$ & NO HITS ${ }^{b}$ & & \\
\hline gtattgaccc & 430 & $0.66 \%$ & Phosphoketolase & $1.00 \mathrm{E}-165 / 1.00 \mathrm{E}-106^{\mathrm{c}}$ & Lactococcus lactis AE006381 \\
\hline aatgacttt & 427 & $0.65 \%$ & NO HITS & & \\
\hline gcgttacttg & 348 & $0.53 \%$ & Zinc transporter & $2 \mathrm{E}-27$ & $\begin{array}{l}\text { Saccharomyces cerevisiae } \\
\text { Z72777 }\end{array}$ \\
\hline tctttgatgt-3' & 328 & $0.50 \%$ & ADP, ATP carrier protein & $1.00 \mathrm{E}-110 / 2.00 \mathrm{E}-72^{\mathrm{c}}$ & $\begin{array}{l}\text { Gossypium hirsutum } \\
\text { AF006489 }\end{array}$ \\
\hline gtcgtagagt & 327 & $0.50 \%$ & Enolase & $1 \mathrm{E}-131$ & S. cerevisiae $\mathrm{j} 01322$ \\
\hline atatgacata & 305 & $0.47 \%$ & Glycine dehydrogenase & 0 & S. pombe Z54308 \\
\hline caagtaattt & 293 & $0.45 \%$ & NO HITS & & \\
\hline catctattcc & 286 & $0.44 \%$ & NO HITS ${ }^{a}$ & & \\
\hline ccagaagttg & 267 & $0.41 \%$ & Mitochondrial thioredoxin & $2 \mathrm{E}-39 / 2.00 \mathrm{E}-54^{\mathrm{C}}$ & S. cerevisiae $\times 59720$ \\
\hline ttcggcaagg $-5^{\prime}$ & 264 & $0.40 \%$ & ADP, ATP carrier protein & 1.00E-115/1.00E-132c & G. hirsutum AF006489 \\
\hline ctccgccgag & 261 & $0.40 \%$ & Pyruvate decarboxylase & $1.00 \mathrm{E}-72 / 3.00 \mathrm{E}-40^{\mathrm{c}}$ & Pichia stipitis U75310 \\
\hline gctctccagg & 250 & $0.38 \%$ & Histone $\mathrm{H} 3$ & $1.00 \mathrm{E}-48 / 9.00 \mathrm{E}-64^{\mathrm{c}}$ & Mortierella alpina AJ249812 \\
\hline gctaacgctg & 238 & $0.36 \%$ & Cyclophilin A & 5.00E-76/2.00E-91 ${ }^{c}$ & C. neoformans AF333996 \\
\hline gtcggtggta & 230 & $0.35 \%$ & ATP synthase- $\beta$-chain & $0.0 / 3.00 \mathrm{E}-43^{\mathrm{c}}$ & Kluyveromyces lactis U37764 \\
\hline tcgagaatgg & 218 & $0.33 \%$ & NO HITS ${ }^{b}$ & & \\
\hline gacgatatat & 204 & $0.31 \%$ & C-4 methyl sterol oxidase & $2 \mathrm{E}-84 / 2.00 \mathrm{E}-48^{\mathrm{c}}$ & S. pombe AL109832 \\
\hline cagagatgtg & 197 & $0.30 \%$ & Nonhistone protein & $1.00 \mathrm{E}-6 / 7.00 \mathrm{E}-9^{\mathrm{c}}$ & S. cerevisiae Z94864 \\
\hline tctggtcgag & 187 & $0.29 \%$ & Histone $\mathrm{H} 4$ & 7.00E-19/2.00E-38 & $\begin{array}{l}\text { Phanerochaete chrysosporium } \\
\text { Z15134 }\end{array}$ \\
\hline aggaagagaa & 186 & $0.28 \%$ & Hypothetical protein & $2.00 \mathrm{E}-22 / 5.00 \mathrm{E}-05^{\mathrm{c}}$ & Agaricus bisporus AJ271701 \\
\hline cgcggaaagg & 184 & $0.28 \%$ & NO HITS ${ }^{a}$ & & \\
\hline aatggtttg & 183 & $0.28 \%$ & NO HITS & & \\
\hline tagccgggaa & 182 & $0.28 \%$ & NO HITS & & \\
\hline tccttccgag & 179 & $0.27 \%$ & GAPDH & $1.00 \mathrm{E}-112 / 0.0^{\mathrm{c}}$ & C. neoformans AF106950 \\
\hline atttccgccg & 178 & $0.27 \%$ & $\begin{array}{l}\text { Serine-threonine protein } \\
\text { kinase }\end{array}$ & $7 \mathrm{E}-65$ & Mus musculus U48737 \\
\hline cacgttcacg & 168 & $0.26 \%$ & Thioredoxin peroxidase & $2.00 \mathrm{E}-39 / 2.00 \mathrm{E}-64^{\mathrm{c}}$ & S. pombe AL031798 \\
\hline ataaaaaaaa & 159 & $0.24 \%$ & NO HITS ${ }^{a}$ & & \\
\hline catattgaat & 157 & $0.24 \%$ & Uracil ribosyl transferase & $3.00 \mathrm{E}-10$ & S. pombe Z98598 \\
\hline gcagatcgat & 154 & $0.24 \%$ & 60 s ribosomal protein RPL39 & $3.00 \mathrm{E}-09 / 1.00 \mathrm{E}-13^{\mathrm{c}}$ & K. marxianus S53434 \\
\hline getcetcta & 152 & $0.23 \%$ & ATP synthase- $\alpha$-chain & $2.00 \mathrm{E}-58 / 9.00 \mathrm{E}-46^{\mathrm{c}}$ & S. pombe M57955 \\
\hline aaagcgcgtt & 151 & $0.23 \%$ & Inositol 1-phosphate synthase & $1 \mathrm{E}-144$ & Pichia pastoris AF078915 \\
\hline agtcctcttc & 150 & $0.23 \%$ & $60 S$ ribosomal protein RPP2 & $1.00 \mathrm{E}-15$ & Alternaria alternata U87806 \\
\hline actacctet & 149 & $0.23 \%$ & Ribosomal protein RPP1 & $1 \mathrm{E}-13$ & C. elegans AF003139 \\
\hline ccatatgttt & 149 & $0.23 \%$ & Glycogen phosphorylase & $6.00 \mathrm{E}-95 / 2.00 \mathrm{E}-40^{\mathrm{c}}$ & $\begin{array}{l}\text { Dictyostelium discoideum } \\
\text { M77492 }\end{array}$ \\
\hline actatcgcet & 142 & $0.22 \%$ & Ubiquitin conjugating enzyme & $8.00 \mathrm{E}-45 / 2.00 \mathrm{E}-75^{\mathrm{c}}$ & $\begin{array}{l}\text { Glomerella cingulata } \\
\text { AF030296 }\end{array}$ \\
\hline cagcagttta & 139 & $0.21 \%$ & NO HITS ${ }^{b}$ & & \\
\hline agtggcagtt & 138 & $0.21 \%$ & Opsin & $0.004 / 3.00 \mathrm{E}-21^{\mathrm{c}}$ & $\begin{array}{l}\text { Leptosphaeria maculans } \\
\text { AF290180 }\end{array}$ \\
\hline cattcgttca & 137 & $0.21 \%$ & NO HITS & & \\
\hline aattcgctt & 133 & $0.20 \%$ & 14-3-3 Protein & $5.00 \mathrm{E}-84 / 1.00 \mathrm{E}-124^{\mathrm{c}}$ & $\begin{array}{l}\text { Schizophyllum commune } \\
\text { AY029473 }\end{array}$ \\
\hline tagcctttcg & 127 & $0.19 \%$ & NO HITS & & \\
\hline cgtgaggctg & 125 & $0.19 \%$ & $\begin{array}{l}\text { 6-Phosphogluconate } \\
\text { dehydrogenase }\end{array}$ & $1.00 \mathrm{E}-170 / 0.0^{\mathrm{C}}$ & \\
\hline catacaggtc & 122 & $0.19 \%$ & Glutamine synthase & $1.00 \mathrm{E}-133 / 1.00 \mathrm{E}-163^{\mathrm{c}}$ & A. bisporus Y12704 \\
\hline ggttacgctg & 121 & $0.19 \%$ & $\begin{array}{l}\text { Mitochondrial malate } \\
\text { dehydrogenase }\end{array}$ & $1.00 \mathrm{E}-115^{\mathrm{c}}$ & S. cerevisiae $\mathrm{J} 02841$ \\
\hline taacgcataa & 117 & $0.18 \%$ & NO HITS ${ }^{b}$ & & \\
\hline ccggctaatg & 117 & $0.18 \%$ & NO HITS ${ }^{b}$ & & \\
\hline acatcgatct & 117 & $0.18 \%$ & $60 S$ ribosomal protein RPL31 & $3 \mathrm{E}-25$ & $\begin{array}{l}\text { Cyanophora paradoxa } \\
\text { AJ005204 }\end{array}$ \\
\hline
\end{tabular}

aSerial analysis of gene expression (SAGE) tag does not have an associated genomic contig at Stanford or expressed sequence tag (EST) at http://www.genome.ou.edu/cneo.html.

bIdentified EST or contig does not have a significant BLASTx result at http://www.ncbi.nlm.nih.gov/.

cEST BLASTx result.

\section{Genome Research}


Table 3B. Top 50 Tags Expressed at $37^{\circ} \mathrm{C}$ for Strain B3501

\begin{tabular}{|c|c|c|c|c|c|}
\hline SAGE tag & $\begin{array}{c}\text { Frequency } \\
(15,363 \\
\text { total) }\end{array}$ & Percentage & $\begin{array}{l}\text { Preliminary gene } \\
\text { designation }\end{array}$ & $\begin{array}{l}\text { E-value of top } \\
\text { BLASTx result }\end{array}$ & $\begin{array}{l}\text { Accession no. } \\
\text { of BLASTx }\end{array}$ \\
\hline cgacagaccg & 207 & $1.35 \%$ & Translation elongation factor 1 & $0.0 / 0.0^{c}$ & C. neoformans U81804 \\
\hline aggaagagaa & 125 & $0.81 \%$ & $\begin{array}{l}\text { Hypothetical protein (Agaricus } \\
\text { bisporus) }\end{array}$ & $2.00 \mathrm{E}-22 / 5.00 \mathrm{E}-05^{\mathrm{c}}$ & A. bisporus AJ271701 \\
\hline aaaaaaaaa & 119 & $0.77 \%$ & NO HITS & & \\
\hline gcgttacttg & 85 & $0.55 \%$ & Zinc transporter & $2.00 \mathrm{E}-27$ & S. cerevisiae Z72777 \\
\hline ctccgccgag & 85 & $0.55 \%$ & Pyruvate decarboxylase & $1.00 \mathrm{E}-72 / 3.00 \mathrm{E}-40^{c}$ & Pichia stipitis U75310 \\
\hline gtcgtagagt & 82 & $0.53 \%$ & Enolase & $1 \mathrm{E}-131$ & S. cerevisiae $\mathrm{J} 01322$ \\
\hline gtcggtggta & 76 & $0.49 \%$ & ATP synthase $-\beta$ chain & $0.0 / 3.00 \mathrm{E}-43^{c}$ & K. lactis U37764 \\
\hline ccagaagttg & 68 & $0.44 \%$ & Mitochondrial thioredoxin & $2.00 \mathrm{E}-39 / 2.00 \mathrm{E}-72^{\mathrm{c}}$ & S. cerevisiae $\mathrm{X} 59720$ \\
\hline aatgactttt & 68 & $0.44 \%$ & NO HITS ${ }^{b}$ & & \\
\hline atatgacata & 67 & $0.44 \%$ & Glycine dehydrogenase & 0 & S. pombe Z54308 \\
\hline cgagtcgtat & 62 & $0.40 \%$ & Iron permease & $2 \mathrm{E}-23$ & S. pombe Z67998 \\
\hline catttacata & 57 & $0.37 \%$ & NO HITS ${ }^{b}$ & & \\
\hline ttcggcaagg $-5^{\prime}$ & 57 & $0.37 \%$ & ADP, ATP carrier protein & $1 \mathrm{E}-115 / 1.00 \mathrm{E}-132^{\mathrm{c}}$ & G. hirsutum AF006489 \\
\hline gaacgatgct & 56 & $0.36 \%$ & NO HITS ${ }^{b}$ & & \\
\hline atatgaaaga & 55 & $0.36 \%$ & NO HITS ${ }^{b}$ & & \\
\hline cgcggaaagg & 54 & $0.35 \%$ & NO HITS ${ }^{a}$ & & \\
\hline gtattgaccc & 52 & $0.34 \%$ & Phosphoketolase & $1.00 \mathrm{E}-165 / 1.00 \mathrm{E}-106^{\mathrm{c}}$ & Lactococcus lactis AE006381 \\
\hline tctttgatgt-3' & 49 & $0.32 \%$ & ADP, ATP carrier protein & $1.00 \mathrm{E}-110 / 2.00 \mathrm{E}-72^{\mathrm{c}}$ & $\begin{array}{l}\text { Gossypium hirsutum } \\
\text { AF006489 }\end{array}$ \\
\hline aacgtctgcc & 45 & $0.29 \%$ & NO HITS ${ }^{a}$ & & \\
\hline attgagatgg & 44 & $0.29 \%$ & NO HITS ${ }^{b}$ & & \\
\hline atttccgccg & 43 & $0.28 \%$ & Serine-threonine protein kinase & $7 \mathrm{E}-65$ & M. musculus U48737 \\
\hline actacctect & 42 & $0.27 \%$ & Ribosomal protein RPP1 & $1.00 \mathrm{E}-13$ & C. elegans AF003139 \\
\hline acgtaccttt & 41 & $0.27 \%$ & NO HITS ${ }^{b}$ & & \\
\hline cacalcctt & 41 & $0.27 \%$ & $\begin{array}{l}\text { Ubiquitin/ribosomal protein } \\
\text { RPS27A fusion protein }\end{array}$ & $6.00 \mathrm{E}-36 / 7.00 \mathrm{E}-40^{c}$ & N. crassa U01220 \\
\hline ggccgacctg & 41 & $0.27 \%$ & Ribosomal protein RPL11 & $2.00 \mathrm{E}-56 / 5.00 \mathrm{E}-73^{\mathrm{c}}$ & S. pombe Z69240 \\
\hline catctattcc & 40 & $0.26 \%$ & NO HITS ${ }^{a}$ & & \\
\hline cacgttcacg & 40 & $0.26 \%$ & Thioredoxin peroxidase & $2.00 \mathrm{E}-39 / 2.00 \mathrm{E}-64^{\mathrm{c}}$ & S. pombe AL031798 \\
\hline gcattggcgt & 39 & $0.25 \%$ & ER chaperone BiP & $0.0 / 5.00 \mathrm{E}-20$ & Aspergillus oryzae $\mathrm{AB} 030231$ \\
\hline actatcgect & 38 & $0.25 \%$ & Ubiquitin conjugating enzyme & $8.00 \mathrm{E}-45 / 2.00 \mathrm{E}-75^{\mathrm{c}}$ & $\begin{array}{l}\text { Glomerella cingulata } \\
\text { AF030296 }\end{array}$ \\
\hline getcgcgacg & 36 & $0.23 \%$ & 60 S ribosomal protein RPL2 & $2.00 \mathrm{E}-72$ & D. melanogaster AF098520 \\
\hline tccttccgag & 36 & $0.23 \%$ & $\begin{array}{l}\text { Glyceraldehyde-3-phosphate } \\
\text { dehydrogenase }\end{array}$ & $1.00 \mathrm{E}-112 / 0.0^{c}$ & C. neoformans AF106950 \\
\hline cctgttctcg & 36 & $0.23 \%$ & NO HIT ${ }^{\mathrm{b}}$ & & \\
\hline tctgtcgagg & 35 & $0.23 \%$ & $40 S$ ribosomal protein RPS12 & $6.00 \mathrm{E}-36 / 7.00 \mathrm{E}-42^{\mathrm{c}}$ & S. pombe AL031154 \\
\hline cattcgttca & 35 & $0.23 \%$ & NO HIT & & \\
\hline tagcetteg & 34 & $0.22 \%$ & NO HIT ${ }^{\mathrm{b}}$ & & \\
\hline atgggetccc & 34 & $0.22 \%$ & ATP synthase- $\gamma$-chain & $6.00 \mathrm{E}-44 / 9.00 \mathrm{E}-66^{\mathrm{c}}$ & S. pombe AL031856 \\
\hline getcctctta & 33 & $0.21 \%$ & ATP synthase- $\alpha$-chain & $2.00 \mathrm{E}-58 / 9.00 \mathrm{E}-46^{\mathrm{c}}$ & S. pombe M57955 \\
\hline acatcgatct & 32 & $0.21 \%$ & $60 S$ ribosomal protein RPL31 & $3 \mathrm{E}-25$ & $\begin{array}{l}\text { Cyanophora paradoxa } \\
\text { AJ005204 }\end{array}$ \\
\hline gcagatcgat & 32 & $0.21 \%$ & 60 S ribosomal protein RPL39 & $3.00 \mathrm{E}-09 / 1.00 \mathrm{E}-13^{\mathrm{c}}$ & K. marxianus S53434 \\
\hline gatgcttttt & 30 & $0.20 \%$ & 605 ribosomal protein RPL19 & $9.00 \mathrm{E}-31$ & S. pombe AB010048 \\
\hline ggttacgctg & 30 & $0.20 \%$ & $\begin{array}{l}\text { Mitochondrial malate } \\
\text { dehydrogenase }\end{array}$ & $1.00 \mathrm{E}-115^{\mathrm{c}}$ & S. cerevisiae J02841 \\
\hline $\operatorname{cggtgcctg} c$ & 30 & $0.20 \%$ & $60 S$ ribosomal protein RPL15 & $3.00 \mathrm{E}-47 / 4.00 \mathrm{E}-88^{\mathrm{c}}$ & Quercus suber AJ001346 \\
\hline aaatggtttg & 29 & $0.19 \%$ & $\mathrm{NO} \mathrm{HIT}^{\mathrm{b}}$ & & \\
\hline gctaacgctg & 29 & $0.19 \%$ & Cyclophilin A & $5.00 \mathrm{E}-76 / 2.00 \mathrm{E}-91^{\mathrm{c}}$ & C. neoformans AF333996 \\
\hline aaccgcacca & 29 & $0.19 \%$ & $\begin{array}{l}\text { Peripheral benzodiazepine } \\
\text { receptor }\end{array}$ & $6.00 \mathrm{E}-16^{\mathrm{c}}$ & Homo sapiens JE0149 \\
\hline agtcctcttc & 28 & $0.18 \%$ & 60 S ribosomal protein RPP2 & $1 \mathrm{E}-15$ & Alternaria alternata U87806 \\
\hline cagcagttta & 28 & $0.18 \%$ & NO HITS ${ }^{b}$ & & \\
\hline cacggcgcat & 27 & $0.18 \%$ & $60 S$ ribosomal protein RPL41 & $2 \mathrm{E}-39$ & C. neoformans AF118148 \\
\hline tagccgggaa & 27 & $0.18 \%$ & NO HITS ${ }^{b}$ & & \\
\hline catagttggt & 27 & $0.18 \%$ & Heat shock protein 70 family & 0 & $\begin{array}{l}\text { Malassezia sympodialis } \\
\text { AJ428052 }\end{array}$ \\
\hline
\end{tabular}

aSerial analysis of gene expression (SAGE) tag does not have an associated contig at Stanford or expressed sequence tag (EST) at http:// www.genome.ou.edu/cneo.html.

'Identified EST does not have a significant BLASTx result at http://www.ncbi.nlm.nih.gov/.

'EST BLASTx result. 
Table 4. B3501 Tags More Highly Expressed at $25^{\circ} \mathrm{C}$

\begin{tabular}{|c|c|c|c|c|c|c|c|c|}
\hline \multirow[b]{2}{*}{ SAGE tag } & \multirow[b]{2}{*}{$\begin{array}{l}\text { B3501 } \\
25\end{array}$} & \multirow[b]{2}{*}{$\begin{array}{c}25 \\
\text { normalized }\end{array}$} & \multirow[b]{2}{*}{$\begin{array}{c}\text { B3501 } \\
37\end{array}$} & \multirow[b]{2}{*}{$\begin{array}{l}\text { FOLD } \\
\text { difference }\end{array}$} & \multirow[b]{2}{*}{$\begin{array}{l}\text { Preliminary gene } \\
\text { designation }\end{array}$} & \multicolumn{2}{|c|}{ E-value } & \multirow[b]{2}{*}{$\begin{array}{l}\text { Accession no. } \\
\text { of BLASTx }\end{array}$} \\
\hline & & & & & & $\begin{array}{l}\text { Genomic } \\
\text { BLASTx }\end{array}$ & $\begin{array}{l}\text { EST } \\
\text { BLASTx }\end{array}$ & \\
\hline caagtaattt & 293 & 69 & 11 & 6.3 & NO HITS & & & \\
\hline gaacgatget & 607 & 143 & 56 & 2.6 & NO HITS ${ }^{b}$ & & & \\
\hline aaagcgcgtt & 151 & 35 & 3 & 11.7 & $\begin{array}{l}\text { Inositol 1-phosphate } \\
\text { synthase }\end{array}$ & $1.00 \mathrm{E}-144$ & & Pichia pastoris AF078915 \\
\hline catttacata & 546 & 128 & 57 & 2.2 & NO HITS ${ }^{b}$ & & & \\
\hline gacgatatat & 204 & 48 & 9 & 5.3 & $\begin{array}{l}\text { C-4 methyl sterol } \\
\text { oxidase }\end{array}$ & $2.00 \mathrm{E}-84$ & $2.00 \mathrm{E}-48$ & $\begin{array}{l}\text { Schizosaccharomyces pombe } \\
\text { AL109832 }\end{array}$ \\
\hline getctccagg & 250 & 59 & 15 & 3.9 & Histone H3 & 2.00E-48 & $9.00 \mathrm{E}-64$ & Mortierella alpina Al249812 \\
\hline cgagtcgtat & 539 & 127 & 62 & 2.0 & Iron permease & $2.00 \mathrm{E}-23$ & & S. pombe Z67998 \\
\hline cagagatgtg & 197 & 46 & 14 & 3.3 & Nonhistone protein & $1.00 \mathrm{E}-06$ & 7.00E-09 & $\begin{array}{l}\text { Saccharomyces cerevisiae } \\
\text { Z94864 }\end{array}$ \\
\hline tatctgaaag & 93 & 22 & 2 & 11.0 & $\begin{array}{l}\text { Delayed-type } \\
\text { hypersensitivity } \\
\text { antigen }\end{array}$ & $1.00 \mathrm{E}-103$ & & $\begin{array}{l}\text { Cryptococcus neoformans } \\
\text { AF246128 }\end{array}$ \\
\hline cattcggttt & 60 & 14 & 0 & unique to 25 & NO HITS & & & \\
\hline gtattgaccc & 430 & 101 & 52 & 1.9 & Phosphoketolase & $1.00 \mathrm{E}-165$ & $1.00 \mathrm{E}-106$ & Lactococcus lactis AE006381 \\
\hline tgatgggaag & 57 & 13 & 0 & unique to 25 & Sterol C-5-desaturase & $1.00 \mathrm{E}-56$ & & Rattus norvegicus AB052846 \\
\hline tcgagaatgg & 218 & 51 & 19 & 2.7 & NO HITS ${ }^{b}$ & & & \\
\hline aattcgettt & 133 & 31 & 8 & 3.9 & 14-3-3-Protein & $5.00 \mathrm{E}-84$ & $1.00 \mathrm{E}-124$ & $\begin{array}{l}\text { Schizophyllum commune } \\
\text { AY029473 }\end{array}$ \\
\hline tatatgtgta & 79 & 19 & 2 & 9.5 & Heat shock protein 12 & 7.50E-02 & $4.00 \mathrm{E}-12$ & S. cerevisiae X55785 \\
\hline ataaaaaaaa & 159 & 37 & 12 & 3.1 & NO HITS ${ }^{a}$ & & & \\
\hline tgaaaatata & 62 & 15 & 1 & 15.0 & $\begin{array}{r}\Delta 9 \text { fatty acid } \\
\text { desaturase }\end{array}$ & $1.00 \mathrm{E}-136$ & $1.00 \mathrm{E}-111$ & Mortierella alpina Y18553 \\
\hline tactettett & 108 & 25 & 6 & 4.2 & NO HITS ${ }^{a}$ & & & \\
\hline tatcccacca & 99 & 23 & 5 & 4.6 & NO HITS ${ }^{b}$ & & & \\
\hline atgatttgag & 77 & 18 & 3 & 6.0 & NO HITS ${ }^{b}$ & & & \\
\hline cctcaacgge & 101 & 24 & 6 & 4.0 & NO HITS ${ }^{b}$ & & & \\
\hline gaactggcgg-3' & 37 & 9 & 0 & unique to 25 & $\begin{array}{l}\text { Adenosyl } \\
\text { homocysteinase }\end{array}$ & $0.00 E+00$ & $2.00 \mathrm{E}-40$ & S. pombe AB004537 \\
\hline agtgctgctg & 63 & 15 & 2 & 7.5 & Histone $\mathrm{H} 1$ & $1.10 \mathrm{E}-02$ & & S. cerevisiae U43703 \\
\hline caaaaaggat & 63 & 15 & 2 & 7.5 & NO HITS ${ }^{b}$ & & & \\
\hline tcaaagaaga & 62 & 15 & 2 & 7.5 & NO HITS & & & \\
\hline ctgaggctga & 50 & 12 & 1 & 12.0 & NO HITS ${ }^{b}$ & & & \\
\hline ggcttgacca & 50 & 12 & 1 & 12.0 & $\begin{array}{l}\text { High-affinity } \\
\text { monosaccharide } \\
\text { transporter }\end{array}$ & $9.00 \mathrm{E}-30$ & 8.00E-48 & Amanita muscaria Z83828 \\
\hline ccggctaatg & 117 & 27 & 9 & 3.0 & NO HITS & & & \\
\hline ctgtatgtcc & 34 & 8 & 0 & unique to 25 & NO HITS ${ }^{b}$ & & & \\
\hline accttgatgg & 78 & 18 & 4 & 4.5 & NO HITS ${ }^{b}$ & & & \\
\hline gacttttgac & 94 & 22 & 6 & 3.7 & NO HITS ${ }^{b}$ & & & \\
\hline tctggtcgag & 187 & 44 & 20 & 2.2 & Histone H4 & 7.00E-19 & $2.00 \mathrm{E}-38$ & Agaris bisporus P35058 \\
\hline ggcatttagt & 32 & 8 & 0 & unique to 25 & NO HITS & & & \\
\hline attggtttga & 32 & 8 & 0 & unique to 25 & NO HITS ${ }^{b}$ & & & \\
\hline getaacgetg & 238 & 56 & 29 & 1.9 & Cyclophilin A & $5.00 \mathrm{E}-76$ & 2.00E-91 & C. neoformans AF333996 \\
\hline ttcgcgetaa & 66 & 16 & 3 & 5.3 & NO HITS ${ }^{b}$ & & & \\
\hline caagcagata & 45 & 11 & 1 & 11.0 & $\begin{array}{l}\text { Fatty acid synthase } \\
\alpha \text {-chain }\end{array}$ & $1.00 \mathrm{E}-68$ & & S. pombe D83412 \\
\hline tatccgggtc & 72 & 17 & 4 & 4.3 & $\begin{array}{l}\text { Aspartate } \\
\text { aminotransferase }\end{array}$ & $6.00 \mathrm{E}-89$ & & Homo sapiens M22632 \\
\hline tctaacccta & 28 & 7 & 0 & unique to 25 & Hmp1 of U. maydis & $1.00 \mathrm{E}-14$ & $1.00 \mathrm{E}-22$ & Ustilago maydis U39049 \\
\hline cacattgata & 70 & 16 & 4 & 4.0 & NO HITS & & & \\
\hline cctgcgagac & 27 & 6 & 0 & unique to 25 & NO HITS ${ }^{b}$ & & & \\
\hline tcataaagca & 26 & 6 & 0 & unique to 25 & NO HITS ${ }^{b}$ & & & \\
\hline tatatccatt & 26 & 6 & 0 & unique to 25 & NO HITS ${ }^{b}$ & $2.00 \mathrm{E}-71$ & & \\
\hline tatcatccgt & 26 & 6 & 0 & unique to 25 & $\begin{array}{l}\text { Myo-inositol } \\
\text { transporter A }\end{array}$ & & $9.00 \mathrm{E}-59$ & N. crassa AL390218 \\
\hline tatgatgttt & 26 & 6 & 0 & unique to 25 & NO HITS & & & \\
\hline catctattcc & 286 & 67 & 40 & 1.7 & NO HITS ${ }^{a}$ & & & \\
\hline tatttgttgt & 25 & 6 & 0 & unique to 25 & $\begin{array}{l}\text { DNA-directed RNA } \\
\text { polymerase II }\end{array}$ & $1.00 \mathrm{E}-91$ & & S. pombe D13337 \\
\hline ttagcgacag & 25 & 6 & 0 & unique to 25 & NO HITS ${ }^{b}$ & & & \\
\hline gtttaatcaa & 24 & 6 & 0 & unique to 25 & $\begin{array}{l}\text { COPII-coated vesicle } \\
\text { component }\end{array}$ & $3.00 \mathrm{E}-18$ & 7.00E-19 & S. pombe AL109831 \\
\hline aatgactttt & 427 & 100 & 68 & 1.5 & NO HITS & & & \\
\hline tctttgatgt- & 328 & 77 & 49 & 1.6 & $\begin{array}{l}\text { ADP, ATP carrier } \\
\text { protein }\end{array}$ & $1.00 \mathrm{E}-133$ & $2.00 \mathrm{E}-72$ & $\begin{array}{l}\text { Gossypium hirsutum } \\
\text { AF006489 }\end{array}$ \\
\hline tgtcataaaa & 23 & 5 & 0 & unique to 25 & NO HITS ${ }^{b}$ & & & \\
\hline
\end{tabular}

$3^{\prime}$ or $5^{\prime}$ denotes that a second serial analysis of gene expression (SAGE) tag was found and that the tag is either the $3^{\prime}$ most tag or more $5^{\prime}$. Tags in this table are differentially expressed with a statistic significance of $P<0.05$.

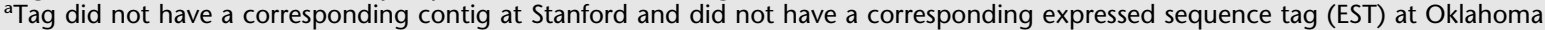

bNo significant BLAST hit results for the genomic or EST sequence associated with the SAGE tag.

\section{Genome Research}




\section{Tags With Higher Levels at $37^{\circ} \mathrm{C}$}

We also made preliminary gene assignments for 50 tags that showed statistically significant elevated levels at $37^{\circ} \mathrm{C}$ (Table 5). The tag with the greatest difference was approximately 47 -fold higher at $37^{\circ} \mathrm{C}$ but represented a transcript from a putative open reading frame on sequence contig cneo010512.Contig5001 with no similarity to known genes. For the other tags, a number of categories of expression were noted that could reflect the adaptation of $C$. neoformans to growth at $37^{\circ} \mathrm{C}$. This adaptation could include changes in the rate of protein synthesis because up-regulated tags matched transcripts for translation elongation factor- $1 \alpha$, a translation initiation factor, and three ribosomal proteins. As well, a change in protein synthesis correlated with the earlier observation that 12 and 11 ribosomal proteins were found in the $37^{\circ} \mathrm{C}$ libraries for both $\mathrm{H} 99$ and $\mathrm{B} 3501$, relative to three and four ribosomal proteins at $25^{\circ} \mathrm{C}$ for $\mathrm{H} 99$ and $\mathrm{B} 3501$, respectively.

We identified tags representing several heat shock proteins (HSP60, HSP70, HSP80) that had higher transcript levels at $37^{\circ} \mathrm{C}$. This observation is particularly interesting in light of observations that heat shock proteins 60 and 70 have been identified as prominent antigens in animals and humans infected with C. neoformans (Kakeya et al. 1997, 1999). The expression of heat shock proteins appears to be a feature of growth in an animal host, and the in vitro growth conditions that we used for the SAGE libraries reflect the host conditions in this regard. The correlation between heat shock gene transcription and growth at $37^{\circ} \mathrm{C}$ is not absolute because we also observed one protein from the heat shock protein 12 family (HSP12) to be up-regulated at $25^{\circ} \mathrm{C}$ (Table $4)$. Interestingly, one of the highest BLASTP results for this putative C. neoformans Hsp12 showed 60\% similarity with Wh11p from C. albicans; the expression of the gene for this protein is not regulated by temperature (Soll 1997). The influence of growth at $37^{\circ} \mathrm{C}$ on both translation elongation machinery and heat shock proteins is consistent with observations in E. coli. Farewell and Neidhardt (1998) have shown that the polypeptide elongation rate increases as a function of temperature and that the rate of elongation appears to be linked mechanistically to the heat shock response. An association between the expression of heat shock proteins and thermotolerance has also been noted in other fungal pathogens such as H. capsulatum (Caruso et al. 1987).

We also found that the collection of tags up-regulated at $37^{\circ} \mathrm{C}$ included genes for two proteases (carboxypeptidase D, serine protease) and a hydroxylase that may be involved in phenolic metabolism (putative salicylate hydroxylase). Our investigation of other tags not included in Table 5 also revealed that transcripts for enzymes involved in phenolic metabolism (aryl-alcohol dehydrogenase and cinnomoyl CoA reductase) were higher at $37^{\circ} \mathrm{C}$ (data not shown). These results indicate a relationship between growth temperature and the metabolism of phenolic compounds in C. neoformans. This may be related to the well-characterized ability of this fungus to convert diphenolic compounds into melanin (Salas et al. 1996; Casadevall and Perfect 1998).

Our results revealed that some genes predicted to encode proteins with iron as a cofactor (aconitase, ubiquinolcytochrome $\mathrm{C}$ reductase) have higher transcript levels at $37^{\circ} \mathrm{C}$ (Table 5). In this regard, Perfect et al. (1998) found that the C. neoformans COX1 gene encoding cytochrome $\mathrm{C}$ oxidase subunit 1 is up-regulated in a rabbit model of in- fection and during a temperature shift from $30^{\circ} \mathrm{C}$ to $37^{\circ} \mathrm{C}$. This indicates an important role for mitochondrial function in the stress response of $C$. neoformans, and our observations indicate a general influence of temperature on respiration and iron homeostasis in C. neoformans. In further support of an influence on iron homeostasis, we observed a tag for a predicted iron permease that was elevated at $25^{\circ} \mathrm{C}$. A similar theme regarding iron homeostasis has emerged from the global analysis of the influence of temperature on transcription in group A Streptococcus (Smoot et al. 2001). As indicated above, the parallels between the responses of group A Streptococcus and C. neoformans to elevated temperature also extended to the expression of the antioxidant protein superoxide dismutase. Our examination of the influence of temperature on gene expression in C. neoformans, although at a relatively early stage, indicates that striking parallels may exist with the response of group A Streptococcus to elevated temperature.

The $37^{\circ} \mathrm{C}$ B3501 library also contained a putative ortholog of a peripheral benzodiazepine receptor (2.68-fold higher at $37^{\circ} \mathrm{C}$ ). The peripheral-type benzodiazepine receptor is localized to the outer mitochondrial membrane and is important for the regulation of cholesterol transport into the mitochondria, a rate-determining step in steroid biosynthesis (Li et al. 2001). Amino acid alignments showed conservation of the cholesterol-binding motif in the cytoplasmic C-terminal domain predicted from the $C$. neoformans sequence (data not shown). In this context, the elevated tag level for this gene might reflect an adaptation at $37^{\circ} \mathrm{C}$ that involves steroid metabolism; this observation is intriguing because of the elevated transcript levels that we observed at $25^{\circ} \mathrm{C}$ for genes involved in sterol biosynthesis.

\section{Tags Representing Putative Regulatory Proteins}

As indicated in Figures 1 and 2, many more tags than those analyzed so far are known to be present at different levels between the two temperatures. As part of our ongoing analysis of the SAGE tags for strain B3501, we performed an initial scan for tags that may represent genes for regulatory proteins in an additional 50 tags at each temperature. Although a complete analysis is not yet possible, we did match tags with genes for several putative proteins of interest. For example, we found a tag (elevated at $37^{\circ} \mathrm{C}$ ) for a gene with similarity to an engrailed-related gene from insects (AATGGATTAA) that functions in development (Marie and Bacon 2000). We also found tags that were elevated at $37^{\circ} \mathrm{C}$ for two WD repeat proteins, one of which showed similarity to the Tup1p global repressor of $S$. cerevisiae (CAGACGCTGT) and the other to the Pop1p protein of $S$. pombe (Kominami et al. 1998). The possibility that a TUP1-like gene is regulated by temperature in $C$. neoformans is intriguing in light of the role of a TUP1 ortholog in the filamentous growth of the fungal pathogen C. albicans (Braun and Johnson 1997). We should note, however, that a BLAST search of the C. neoformans genomic database with the Tup1p sequence of $C$. albicans revealed a gene with a greater level of sequence similarity than the one identified by our SAGE tag. The possibility of temperature control of a global regulator like Tup1p is interesting, however, because it has recently been shown that diploid strains of $C$. neoformans shows a temperature-dependent shift between budding $\left(37^{\circ} \mathrm{C}\right)$ and filamentous growth $\left(24^{\circ} \mathrm{C}\right.$; Sia et al. 2000). As we identify additional temperature regulated genes in our SAGE analysis, it will be possible to screen for C. neoformans or- 
Table 5. B3501 Tags More Highly Expressed at $37^{\circ} \mathrm{C}$

\begin{tabular}{|c|c|c|c|c|c|c|c|c|}
\hline \multirow[b]{2}{*}{ SAGE tag } & \multirow[b]{2}{*}{$\begin{array}{l}\text { B3501 } \\
37\end{array}$} & \multirow[b]{2}{*}{$\begin{array}{l}\text { B3501 } \\
25\end{array}$} & \multirow[b]{2}{*}{$\begin{array}{c}25 \\
\text { normalized }\end{array}$} & \multirow[b]{2}{*}{$\begin{array}{l}\text { FOLD } \\
\text { difference }\end{array}$} & \multirow[b]{2}{*}{$\begin{array}{l}\text { Preliminary gene } \\
\text { designation }\end{array}$} & \multicolumn{2}{|c|}{ E-value } & \multirow[b]{2}{*}{$\begin{array}{l}\text { Accession no. } \\
\text { of BLASTx }\end{array}$} \\
\hline & & & & & & $\begin{array}{l}\text { Genome } \\
\text { BLASTx }\end{array}$ & $\begin{array}{c}\text { EST } \\
\text { BLASTx }\end{array}$ & \\
\hline atatgaaaga & 55 & 5 & 1 & 55.0 & NO HITS ${ }^{b}$ & & & \\
\hline aggaagagaa & 125 & 186 & 44 & 2.8 & Hypothetical protein & & $4.00 \mathrm{E}-22$ & Agaris bisporus AJ271701 \\
\hline acgtacctt & 41 & 21 & 5 & 8.2 & NO HITS & & & \\
\hline cgacagaccg & 207 & 529 & 124 & 1.7 & $\begin{array}{l}\text { Translation elongation } \\
\text { factor } 1 \alpha\end{array}$ & $0.00 \mathrm{E}+00$ & $0.00 E+00$ & $\begin{array}{l}\text { Cryptococcus neoformans } \\
\text { U81804 }\end{array}$ \\
\hline ggaatttgct & 24 & 17 & 4 & 6.0 & NO HITS ${ }^{b}$ & & & \\
\hline tagacagact & 15 & 6 & 1 & 15.0 & Carboxypeptidase D & $1.00 \mathrm{E}-121$ & & P. janthinellum AAB35195.1 \\
\hline accgacgtga & 22 & 19 & 4 & 5.5 & Aconitate hydratase & $1.00 \mathrm{E}-165$ & & Piromyces sp Y16747 \\
\hline cggaaaaaac & 7 & 0 & 0 & unique to 37 & Hypothetical protein & 1.00E-11 & & $\begin{array}{l}\text { Arabidopsis thaliana } \\
\text { AC002294 }\end{array}$ \\
\hline cctgttctcg & 36 & 51 & 12 & 3.0 & NO HITS ${ }^{b}$ & & & \\
\hline gccgettctg & 13 & 6 & 1 & 13.0 & $\begin{array}{l}\text { Ubiquinol-cytochrome } \\
\text { C reductase } \\
\text { iron-sulfur }\end{array}$ & $1.00 \mathrm{E}-84$ & & Neurospora crassa X02472 \\
\hline aaccagcggt & 8 & 1 & 0 & 34.1 & Salicylate hydroxylase & $3.00 \mathrm{E}-12$ & & $\begin{array}{l}\text { Streptomyces coelicolor } \\
\text { AL035707 }\end{array}$ \\
\hline aagacatcgt & 9 & 2 & 0 & 19.2 & NO HITS & & & \\
\hline attttagaaa & 9 & 2 & 0 & 19.2 & $\begin{array}{l}\text { NADH-ubiquinone } \\
\text { oxidoreductase } \\
\text { subunit }\end{array}$ & $6.00 \mathrm{E}-07$ & & N. crassa X60829 \\
\hline gtccataagg & 13 & 7 & 2 & 6.5 & NO HITS & & & \\
\hline taactcgcat & 6 & 0 & 0 & unique to 37 & NO HITS ${ }^{b}$ & & & \\
\hline tctaagtata & 6 & 0 & 0 & unique to 37 & NO HITS ${ }^{b}$ & & & \\
\hline aacgtctgcc & 45 & 80 & 19 & 2.4 & NO HITS ${ }^{a}$ & & & \\
\hline cgcgcgatgc & 16 & 14 & 3 & 5.3 & NO HITS ${ }^{b}$ & & & \\
\hline gcattggcgt & 39 & 70 & 16 & 2.4 & ER chaperone BiP & $0.00 E+00$ & $5.00 \mathrm{E}-20$ & Aspergillus oryzae $\mathrm{AB} 030231$ \\
\hline catctggatg & 5 & 0 & 0 & unique to 37 & NO HITS & & & \\
\hline tgttatcggt & 16 & 15 & 4 & 4.0 & Heat shock protein 80 & $1.00 \mathrm{E}-135$ & & N. crassa AL513463 \\
\hline gcattttggg & 18 & 20 & 5 & 3.6 & $\begin{array}{l}\text { Ubiquinol-cytochrome } \\
\text { C }\end{array}$ & $1.00 \mathrm{E}-34$ & & N. crassa Y08841 \\
\hline aaccgcacca & 29 & 46 & 11 & 2.6 & $\begin{array}{l}\text { Reductase core } \\
\text { protein peripheral } \\
\text { benzodiazepine } \\
\text { receptor-human }\end{array}$ & & $6.00 \mathrm{E}-16$ & Homo sapiens JE0149 \\
\hline tgtagtatct & 13 & 11 & 3 & 4.3 & NO HITS ${ }^{b}$ & & & \\
\hline tcgagtttca & 11 & 8 & 2 & 5.5 & NO HITS & & & \\
\hline attgagatgg & 44 & 91 & 21 & 2.1 & NO HITS ${ }^{b}$ & & & \\
\hline ctaggttatg & 4 & 0 & 0 & unique to 37 & $\begin{array}{l}3^{\prime} \text { to } 5^{\prime} \text { DNA/RNA } \\
\text { helicase }\end{array}$ & $1.00 \mathrm{E}-165$ & & $\begin{array}{l}\text { Schizosaccharomyces pombe } \\
\text { AL590902 }\end{array}$ \\
\hline ccgectgecg & 4 & 0 & 0 & unique to 37 & NO HITS ${ }^{b}$ & & & \\
\hline gctgcaagcg & 4 & 0 & 0 & unique to 37 & Hypothetical protein & $2.00 \mathrm{E}-43$ & & N. crassa AL513463 \\
\hline ttcgcggtag & 4 & 0 & 0 & unique to 37 & NO HITS ${ }^{\mathrm{b}}$ & & & \\
\hline gtgatggtgg & 4 & 0 & 0 & unique to 37 & NO HITS ${ }^{b}$ & & & \\
\hline ccctacgaga & 4 & 0 & 0 & unique to 37 & NO HITS ${ }^{a}$ & & & \\
\hline atcgcgatgt & 4 & 0 & 0 & unique to 37 & Putative protein & $4.00 \mathrm{E}-05$ & & Mus musculus NM_025872 \\
\hline gggagccata & 4 & 0 & 0 & unique to 37 & NO HITS ${ }^{\mathrm{b}}$ & & & \\
\hline atcctttgtc & 4 & 0 & 0 & unique to 37 & NO HITS ${ }^{b}$ & & & \\
\hline actcaaccgt & 10 & 7 & 2 & 5.0 & NO HITS ${ }^{b}$ & & & \\
\hline catagttggt & 27 & 47 & 11 & 2.5 & $\begin{array}{l}\text { Heat shock protein } 70 \\
\text { family }\end{array}$ & $0.00 \mathrm{E}+00$ & & $\begin{array}{l}\text { Malassezia sympodialis } \\
\text { AJ428052 }\end{array}$ \\
\hline ctcaagaagg & 17 & 22 & 5 & 3.4 & $\begin{array}{l}\text { Subtilisin-like serine } \\
\text { protease }\end{array}$ & 4.00E-91 & & $\begin{array}{l}\text { Penicillium citrinum } \\
\text { AF098517 }\end{array}$ \\
\hline tcagaaccgt & 6 & 2 & 0 & 12.8 & NO HITS ${ }^{b}$ & & & \\
\hline cagaacaaag & 5 & 1 & 0 & 21.3 & $\begin{array}{l}\text { protein with similarity } \\
\text { to } \\
\text { GAPDH }\end{array}$ & $3.00 \mathrm{E}-28$ & & $\begin{array}{l}\text { Mesorhizobium loti } \\
\text { AP003004 }\end{array}$ \\
\hline tatggetgga & 5 & 1 & 0 & 21.3 & NO HITS ${ }^{b}$ & & & \\
\hline gaagtccgga & 5 & 1 & 0 & 21.3 & NO HITS ${ }^{b}$ & & & \\
\hline tacactgtcg & 12 & 12 & 3 & 4.0 & NO HITS ${ }^{b}$ & & & \\
\hline gtttatggaa & 11 & 11 & 3 & 3.7 & Heat shock protein 60 & $0.00 \mathrm{E}+00$ & & Coccidioides immitis U81786 \\
\hline aacgtaaagc & 7 & 4 & 1 & 7.0 & NO HITS ${ }^{b}$ & & & \\
\hline gtgtggggca & 7 & 4 & 1 & 7.0 & NO HITS & & & \\
\hline caacgtagaa & 7 & 4 & 1 & 7.0 & NO HITS ${ }^{b}$ & & & \\
\hline tcatcaccat & 7 & 4 & 1 & 7.0 & $\begin{array}{l}\text { Translation initiation } \\
\text { factor } 3\end{array}$ & $6.00 \mathrm{E}-15$ & & $\begin{array}{l}\text { Myxococcus xanthus } \\
\text { AF261103 }\end{array}$ \\
\hline aactcgtgaa & 15 & 20 & 5 & 3.0 & Hypothetical protein & $2.00 \mathrm{E}-22$ & $5.00 \mathrm{E}-05$ & A. bisporus Al271701 \\
\hline gcggtgggat & 14 & 18 & 4 & 3.5 & NO HITS & & & \\
\hline
\end{tabular}

$3^{\prime}$ or $5^{\prime}$ denotes that a second serial analysis of gene expression (SAGE) tag was found and that the tag is either the $3^{\prime}$ most tag or more $5^{\prime}$. Tags in this table are differentially expressed with a statistic significance of $P<0.05$.

aTag did not have a corresponding contig at Stanford and did not have a corresponding expressed sequence tag (EST) at Oklahoma.

${ }^{b}$ No significant BLAST hit results for the genomic or EST sequence associated with the SAGE tag.

\section{Genome Research}


thologs of genes known to regulated by Tup1p in $S$. cerevisiae and C. albicans (Braun et al. 2000; Wu et al. 2001).

\section{Confirmation of SAGE Results by RNA Blot Analysis}

RNA blot analysis was used to confirm that the observed differences in tag levels reflected differences in transcript levels. As shown in Figure 3A, the transcript level for a putative heat shock 70 protein was found to be elevated at $37^{\circ} \mathrm{C}$ compared with $25^{\circ} \mathrm{C}$; this result was predicted by the SAGE data, which indicated an approximately twofold higher RNA expression at $37^{\circ} \mathrm{C}$. Similarly, the RNA level detected for a predicted monosaccharide transporter gene from B3501 was found to be higher at $25^{\circ} \mathrm{C}$ compared with $37^{\circ} \mathrm{C}$, as predicted by the SAGE results ( 12-fold higher; Fig. 3B). The differential RNA levels indicated by the SAGE results were also confirmed by RNA blot analysis for eight additional genes, and all hybridization experiments were performed with two independent preparations of RNA from cells grown at the two temperatures (data not shown). Overall, the hybridization results support the conclusion that SAGE accurately identified genes with transcript levels that are influenced by temperature.

\section{Summary}

This report describes the first genome-wide analysis of the temperature-regulated transcriptome of $C$. neoformans. The results indicate that the transcript levels for a large number of genes are influenced by growth temperature in this fungal pathogen and that differences exist in the response of different varieties. Our data indicate that the fungus may respond

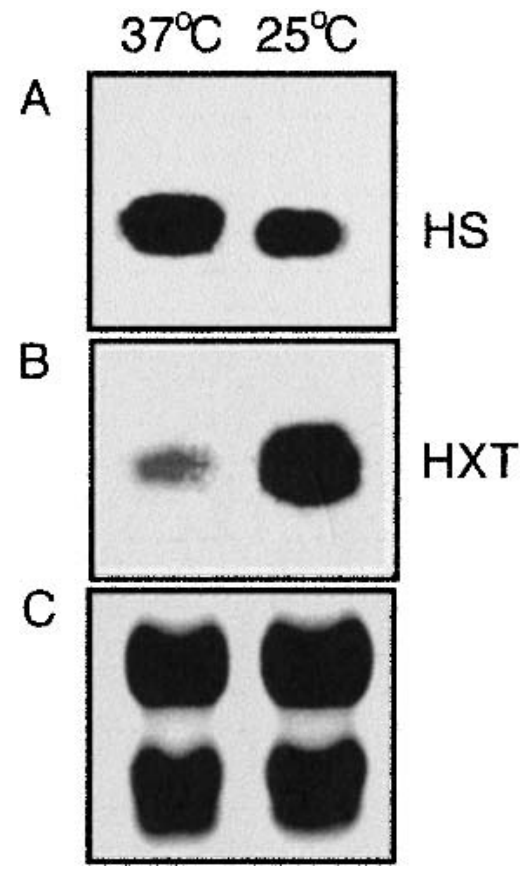

Figure 3 RNA blot analysis of two representative temperatureregulated genes in strain B3501. The RNA was isolated from cells grown at $25^{\circ} \mathrm{C}$ or $37^{\circ} \mathrm{C}$. (A) Hybridization with a polymerase chain reaction (PCR) amplicon from a gene for a heat shock protein 70 (tag, CATAGTTGGT) with a higher transcript level at $37^{\circ} \mathrm{C}(\mathrm{HS})$. (B) Hybridization with a PCR amplicon from a gene for a high-affinity monosaccharide transporter (tag, GGCTTGACCA) with a higher transcript level at $25^{\circ} \mathrm{C}$ (HXT). (C) Ribosomal RNA (18S and 28S) bands as a loading control. to temperature with a change in chromatin packaging, as indicated by the differential transcript levels for histone genes. At $37^{\circ} \mathrm{C}$, the fungus responds by elevating transcript levels for heat shock proteins, translation machinery components, mitochrondrial proteins, and stress proteins such as superoxide dismutase. These results indicate that elevated temperature is a stressful condition for this fungus. It will be interesting to examine whether this pattern is reinforced by a more detailed analysis of the H99 strain because isolates of this serotype (A) are more commonly associated with infections in North America, and strains of this serotype are generally more heat tolerant (Martinez et al. 2001). The completion and annotation of the genomic sequence for $C$. neoformans will allow a more detailed exploration of the generalities of the differential expression described above, and allow the identification of new patterns of temperature-regulated gene expression. Finally, even at this level of analysis at which the genomes of strains H99 and B3501 are only partially characterized, we noticed significant differences between the two strains and intriguing similarities with expression patterns for group A Streptococcus in terms of connections between temperature, iron homeostasis, and the stress response. These observations may reflect a general response of pathogens to growth at host temperature. Of course, the in vitro conditions used here do not adequately mimic the host environment, and transcriptional changes that reflect the pathogen response to the host immune system and host nutritional conditions may not be identified. To address this limitation, additional SAGE experiments are underway with $C$. neoformans cells isolated from infected animals or grown under iron limiting conditions. Finally, the SAGE tags generated in this study will be useful for the annotation of the Cryptococcus genome, particularly in the identification of transcribed regions.

\section{METHODS}

\section{Strains and Growth Conditions}

C. neoformans serotype A, MAT $\alpha$ strain H99 and serotype D, MAT $\alpha$ strain B3501 were supplied by J. Heitman (Duke University) and J. Kwon-Chung (National Institutes of Health), respectively. For SAGE library construction, 2-mL cultures of yeast extract, peptone, dextrose broth were inoculated with single colonies and grown overnight at $30^{\circ} \mathrm{C}$ in a gyratory shaker $(250 \mathrm{rpm})$. The cells from $1 \mathrm{~mL}$ of the culture were collected by centrifugation, washed twice with yeast nitrogen base broth, and resuspended in $1 \mathrm{~mL}$ of YNB buffered with 50 $\mathrm{mM}$ 3-[N-morpholino] propanesulfonic acid ( $\mathrm{pH}$ 7.0). One hundred microliters of washed cells were used to inoculate 50 $\mathrm{mL}$ of the same medium in a sterilized 1-L Erlenmeyer flask. Cultures were grown at either $25^{\circ} \mathrm{C}$ or $37^{\circ} \mathrm{C}$ in a gyratory shaker until early log phase $\left(\mathrm{OD}_{600} \cong 14.0\right)$. The cells for mRNA isolation were in the exponential phase of growth, and the growth rate was similar at both temperatures (data not shown). Cells were harvested by centrifugation and immediately flash frozen in a dry ice-ethanol bath.

\section{RNA Isolation and Analysis}

Frozen cell pellets were lyophilized overnight at $-20^{\circ} \mathrm{C}$ until dry and resuspended in $15 \mathrm{~mL}$ of TRIZOL extraction buffer (GIBCO BRL). Total RNA was isolated according to the manufacturer's recommendations with the addition of an overnight $\mathrm{LiCl}$ precipitation at $4^{\circ} \mathrm{C}$ following the standard ethanol precipitation step. PolyA+ RNA was isolated using the MessageMaker kit (GIBCO BRL). RNA blot preparation and hybridization was performed as described (Sambrook et al. 1989). A hybridization probe was prepared for a gene encod- 
ing high-affinity monosaccharide transporter (tag, CATGGGCTTGACCA) using the primers 5'-AAGATAAGGAG TAATGACGGGCGA-3' and 5'-CTATTGGTGAAATTTTCCCA3' (107-bp amplicon). The primers for the heat shock gene were 5'-ATGGTTCACCGACGTCCAGA-3' and 5-'GCCACC GAAATGCCTGTCAT-3' (262-bp amplicon). These DNAs were labeled with an Oligolabeling kit (Amersham Pharmacia Biotech Inc.).

\section{SAGE Analysis}

SAGE was performed as described by Velculescu et al. (1995) using the protocol available at www.sagenet.org. Poly-A RNA was converted to double-stranded cDNA using the GIBCO $\mathrm{BRL}$ synthesis kit and biotinylated oligo- $\mathrm{dT}_{18}$. Briefly, the cDNA was cleaved with NlaIII, the 3 '-terminal cDNA fragments were bound to streptavidin beads (Dynal), and oligonucleotide linkers containing BsmFI restriction sites were ligated to the $5^{\prime}$ ends. The linkered cDNA was released from the streptavidin bead by BsmFI digestion, and tags were ligated to one another, polymerase chain reaction (PCR) amplified, concatemerized, and cloned into the SphI site of pZERO 1.0 (Invitrogen). Twenty-eight PCR cycles were used to amplify ditags during library construction. Colonies were screened by PCR (M13F and M13R primers) to assess the average clone insert size and percentage of nonrecombinants. Tags were obtained by BigDye primer cycle sequencing and analysis on an ABI PRISM 3700 DNA analyzer. Sequence chromatograms were processed using Phred (Ewing and Green 1998; Ewing et al. 1998) and vector sequence detected using CROSS_MATCH (Gordon et al. 1998). Fourteen-bp tags were extracted from the vector clipped sequence, and an overall quality score for each tag was derived based on the cumulative Phred score. Duplicate di-tags and linker sequences were removed as decribed (Velculescu et al. 1995). Only tags with a predicted accuracy of $\geq 99 \%$ were used in this study. Statistical differences between tag abundance in different libraries was determined using the G-test (Sokal and Rohlf 1991) and the methods of Audic and Claverie (1997).

\section{Tag Identification}

To make preliminary assignments of tags to genes, we used the shotgun sequence data from the $C$. neoformans Genome Project (assemblies 010512 and 011005), Stanford Genome Technology Center (http://www-sequence.stanford.edu; funded by the National Institute of Allergy and Infectious Diseases (NIAID)/National Institutes of Health under cooperative agreement AI47087) and at TIGR (http://www.tigr.org/ $\mathrm{tdb} / \mathrm{edb}$ /crypt/htmls/index.shtml). A limited amount of genomic shotgun sequence data is also available for strain H99 from our BAC clone end sequencing (see accompanying paper by Schein et al. in this issue) and at the Duke University Center for Genome Technology (http://cgt.genetics.duke.edu/ data/index.html). In addition, limited EST databases are available for strains JEC21 and H99 at the University of Oklahoma's Advanced Center for Genome Technology (http:// www.genome.ou.edu/cneo.html, funded under the cooperative agreement UO1 AI 485 94-01). We restricted our analysis to those genes for which an unambiguous tag assignment could be obtained either by annotation of the Stanford genomic data for JEC21 (assembly) or by analysis of ESTs from JEC21 or H99. BLASTx (basic local alignment search tool) results were recorded for those genes that had significant similarity with other proteins in the nonredundant database and National Center for Biotechnology Information (NCBI). Expect values and tentative gene assignments were recorded for those tags that were found to correspond to the $3^{\prime}$ most NlaIII site within the putative open reading frame or within a 3' untranslated region. In addition, the BLASTx results were inspected individually. In some cases, we found a high Expect value when the alignment of the protein from the nonredun- dant database and the C. neoformans sequence showed significant identity such that the Expect value did not reflect the extent of similarity. This occurred most frequently with small proteins. Because of the presence of introns in the genomic sequence and the length of the contigs, the Expect values recorded here are much lower than those that would be found if introns were removed, sequences were translated, and BLASTP analysis was performed. For the preliminary identification of ribosomal proteins, our nomenclature followed the outlined standards for S. cerevisiae (Mager et al. 1997). It should be noted that $C$. neoformans genes typically have an average of 5.6 introns per gene, and this complicates unambiguous identification of the 3' end of genes. We did note that tags were often near a putative polyadenylation signal that corresponded with the consensus sequence AAC/GAAA similar to what has been observed previously (Chaturvedi et al. 2001).

\section{ACKNOWLEDGMENTS}

We thank Jacquie Schein and Duane Smailus for contributing support for this work along with the GSC sequencing team (S. Chan, R. Guin, M. Krzywinski, R. Kutsche, C. Mathewson, P. Pandoh, A. Prabhu, J. Stott, M. Tsai, and G. Yang). We thank Jennifer Gorlach, John Perfect and Dena Toffaletti for advice on RNA isolation. We gratefully acknowledge Richard Hyman, Eula Fung, Don Rowley, and Ron Davis at the Stanford Genome Technology Center, funded by the cooperative agreement U01 AI47087; Brendan Loftus and Claire Fraser at The Institute for Genomic Research, funded by the NIAID/ National Institutes of Health under cooperative agreement U01 AI48594 for access to the Cryptococcus Genome Project data; Bruce A. Roe, Doris Kupfer, Jennifer Lewis, Sola Yu, Kent Buchanan, Dave Dyer, and Juneann Murphy at the University of Oklahoma for access to the Cryptococcus neoformans cDNA Sequencing Project (strains JEC21 and H99; National Insitutes of Health-NIAID grant number AI147079); and Fred Dietrich at the Duke Centre for Genome Technology for access to the Duke University database (strain H99). This work was supported by grants from the Canadian Institutes of Health Research (to J.W.K.) and the Natural Sciences and Engineering Research Council of Canada (NSERC) Genomics Program (to S.J., J.W.K. and M.M.) and by a Scholar Award in pathogenic mycology from the Burroughs Wellcome Fund (to J.W.K.). M.M. is a Michael Smith Foundation for Health Research Biomedical Scholar.

The publication costs of this article were defrayed in part by payment of page charges. This article must therefore be hereby marked "advertisement" in accordance with 18 USC section 1734 solely to indicate this fact.

\section{REFERENCES}

Aguilar, P.S., Cronan, Jr., J.E., and de Mendoza, D. 1998. A Bacillus subtilis gene induced by cold shock encodes a membrane phospholipid desaturase. J. Bacteriol. 180: 2194-2200.

Alspaugh, J.A., Perfect, J.R., and Heitman, J. 1997. Cryptococcus neoformans mating and virulence are regulated by the G-protein $\alpha$ subunit GPA1 and cAMP. Genes Dev. 11: 3206-3217.

Alspaugh, A.J., Cavallo, L.M., Perfect, J.R., and Heitman, J. 2000. RAS1 regulates filamentation, mating and growth at high temperature of Cryptococcus neoformans. Mol. Microbiol. 36: 352-365.

Alspaugh, J.A., Pukkila-Worley, R., Harashima, T., Cavallo, L.M., Funnell, D., Cox, G.M., Perfect, J.R.,. Kronstad, J.W., and Heitman J. 2002. Adenylyl cyclase functions downstream of the $\mathrm{G} \alpha$ protein GPA1 and controls mating and pathogenicity in Cryptococcus neoformans. Euk. Cell. 1: 75-84.

Audic, S. and Claverie, J.-M. 1997. The significance of digital gene expression profiles. Genome Res. 7: 986-995.

Bemis, D.A., Krahwinkel, D.J., Bowman, L.A., Mondon, P., and Kwon-Chung, K.J. 2000. Temperature-sensitive strain of Cryptococcus neoformans producing hyphal elements in a feline nasal granuloma. J. Clin. Microbiol. 38: 926-928. 
Braun, B.R. and Johnson, A.D. 1997. Control of filament formation in Candida albicans by the transcriptional repressor TUP1. Science 277: 105-109.

Braun, B.R., Head, S.W., Wang, M.X., and Johnson, A.D. 2000. Identification and characterization of TUP1-regulated genes in Candida albicans. Genetics 156: 31-44.

Caruso, M., Sacco, M., Medoff, G., and Maresca, B. 1987. Heat shock 70 gene is differentially expressed in Histoplasma capsulatum strains with different levels of thermotolerance and pathogenicity. Mol. Microbiol. 1: 151-158.

Casadevall, A. and. Perfect, J.R. 1998. Cryptococcus neoformans. ASM Press, Washington, D.C.

Chang, Y.C. and Kwon-Chung, K.J. 1998. Isolation of a third capsule-associated gene, CAP60, required for virulence in Cryptococcus neoformans. Infect. Immun. 66: 2230-2236.

Chaturvedi, S., Hamilton, A.J., Hobby, P., Zhu, G., Lowry, C.V., and Chaturvedi, V. 2001. Molecular cloning, phylogenetic analysis and three-dimensional modeling of $\mathrm{Cu}, \mathrm{Zn}$ superoxide dismutase (CnSOD1) from three varieties of Cryptococcus neoformans. Gene 268: $41-51$.

Currie, B., Sanati, H., Ibrahim, A.S., Edwards, J.E., Casadevall, A., and Ghannoum, M.A. 1995. Sterol compositions and susceptibilities to amphotericin B of environmental Cryptococcus neoformans isolates are changed by murine passage. Antimicrob. Agents Chemother. 39: 1934-1937.

D'Souza, C.A., Alspaugh, J.A., Yue, C., Harashima, T., Cox, G.M., Perfect, J.R., and Heitman, J. 2001. Cyclic AMP-dependent protein kinase controls virulence of the fungal pathogen Cryptococcus neoformans. Mol. Cell. Biol. 21: 3179-3191.

Ewing, B. and Green, P. 1998. Base-calling of automated sequencer traces using phred, II: Error probabilities. Genome Res. 8: $186-194$

Ewing, B., Hillier, L., Wendl, M.C., and Green, P. 1998. Base-calling of automated sequencer traces using phred, I: Accuracy assessment. Genome Res. 8: 175-185.

Farewell, A. and Neidhardt, F.C. 1998. Effect of temperature on in vivo protein synthetic capacity in Escherichia coli. J. Bacteriol. 180: $4704-4710$.

Gasch, A.P., Spellman, P.T., Kao, C.M., Carmel-Harel, O., Eisen, M.B., Storz, G., Botsein, D., and Brown, P.O. 2000. Genomic expression programs in the response of yeast cells to environmental changes. Mol. Biol. Cell 11: 4241-4257.

Gordon, D., Abajian, C., and Green, P. 1998. Consed: A graphical tool for sequence finishing. Genome Res. 8: 195-202.

Harrison, T.S. 2000. Cryptococcus neoformans and Cryptococcosis. J. Infect. 41: 12-17.

Heitman, J., Allen, B., Alspaugh, J.A., and Kwon-Chung, K.J. 1999a. On the origins of congenic MAT $\alpha$ and MATa strains of the pathogenic yeast Cryptococcus neoformans. Fungal Genet. Biol. 28: $1-5$.

Heitman, J., Casadevall, A., Lodge, J.K., and Perfect, J.R. 1999b. The Cryptococcus neoformans genome sequencing project. Mycopathologia 148: 1-7.

Jacobson, E.S., Jenkins, N.D., and Todd, J.M. 1994. Relationship between superoxide dismutase and melanin in a pathogenic fungus. Infect. Immun. 62: 4085-4086.

Jones, S.J., Riddle, D.L., Pouzyrev, A.T., Velculescu, V.E., Hillier, L., Eddy, S.R., Stricklin, S.L., Baillie, D.L., Waterston, R., and Marra, M,A. 2001. Changes in gene expression associated with developmental arrest and longevity in Caenorhabditis elegans. Genome Res. 11: 1346-1352.

Kakeya, H., Udono, H., Ikuno, N., Yamamoto, Y., Mitsutake, K., Miyazaki, T., Tomono, K., Koga, H., Tashiro, T., Nakayama, E., et al. 1997. A 77-kilodalton protein of Cryptococcus neoformans, a member of the heat shock protein 70 family, is a major antigen detected in the sera of mice with pulmonary cryptococcosis. Infect. Immun. 65: 1653-1658.

Kakeya, H., Udono, H., Maesaki, S., Sasaki, E. Kawamura, S., Hossain M.A., Yamamoto, Y., Sawai, T., Fukuda, M., Mitsutake, K., et al. 1999. Heat shock protein 70 (hsp70), as a major target of the antibody response in patients with pulmonary cryptococcosis. Clin. Exp. Immunol. 115: 485-490.

Kominami, K., Ochotorena, I., and Toda, T. 1998. Two F-box/WD-repeat proteins Pop1 and Pop2 form hetero- and homo-complexes together with cullin-1 in the fission yeast SCF (Skp1-Cullin-1-F-box) ubiquitin ligase. Genes Cells 3: 721-735.

Kwon-Chung, K.J. and Bennett, J.E. Cryptococcosis. In Medical mycology. 1992. (eds. K.J. Kwong-Chung and J.E. Bennett), pp. 397-446. Lea \& Febiger, Malvern, PA.

Kwon-Chung, K.J. and Rhodes, J.C. 1986. Encapsulation and melanin formation as indicators of virulence in Cryptococcus neoformans. Infect. Immun. 51: 218-223.

Kwon-Chung, K.J., Edman, J.C., and Wickes, B.L. 1992. Genetic association of mating types and virulence in Cryptococcus neoformans. Infect. Immun. 60: 602-605.

Lee, S.M. and Park, J.W. 1998. Thermosensitive phenotype of yeast mutant lacking thioredoxin peroxidase. Arch. Biochem. Biophys. 359: $99-106$

Li, H., Yao, Z-X., Degenhardt, B., Teper, G., and Papadopoulos, V. 2001. Cholesterol binding at the cholesterol recognition/interaction amino acid consensus (CRAC) of the peripheral-type benzodiazepine receptor and inhibition of steroidogenesis by an HIV TAT-CRAC peptide. Proc. Natl. Acad. Sci. 98: 1267-1272.

Los, D.A., Ray, M.K., and Murata, N. 1997. Differences in the control of the temperature-dependent expression of four genes for desaturases in Synechocystis sp. PCC6803. Mol. Microbiol. 25: $1167-1175$.

Luberto, C., Toffaletti, D.L., Wills, E.A., Tucker, S.C., Casadevall, A., Perfect, J.R., Hannun, Y.A., and Del Poeta, M.M. 2001. Roles for inositol-phosphoryl ceramide synthase 1 (IPC1) in pathogenesis of C. neoformans. Genes Dev. 15: 201-212.

Mager, W.H., Planta, R.J., Ballesta, J.-P.G., Lee, J.C., Mizuta, K., Suzuki, K., Warner, J.R., and Woolford, J. 1997. A new nomenclature for the cytoplasmic ribosomal proteins of Saccharomyces cerevisiae. Nucl. Acids Res. 25: 4872-4875.

Maresca, B.L., Carratu, L., and Kobayashi, G.S. 1994. Morphological transition in the human fungal pathogen Histoplasma capsulatum. Trends Microbiol. 2: 110-114.

Marie, B. and Bacon, J.P. 2000. Two engrailed-related genes in cockroach: Cloning, phylogenetic analysis, expression and isolation of splice variants. Dev. Genes Evol. 210: 436-448.

Martinez, L.R., Garcia-Rivera, J., and Casadevall, A. 2001. Cryptococcus neoformans var. neoformans (serotype D) strains are more susceptible to heat than C. neoformans var. grubii (serotype A) strains. J. Clin. Microbiol. 39: 3365-3367.

Medoff, G., Painter, A., and Kobayashi, G.S. 1987. Mycelial to yeast phase transitions of the dimorphic fungi Blastomyces dermatitidis and Paracoccidiodes brasiliensis. J. Bacteriol. 169: 4055-4060.

Nakayama, H., Mio, T., Nagahashi, S., Kokado, M., Arisawa, M., and Aoki, Y. 2000. Tetracycline-regulatable system to tightly control gene expression in the pathogenic fungus Candida albicans. Infect. Immun. 68: 6712-6719.

Nosanchuk, J.D., Rosas, A.L., Lee, C., and Casadevall, A. 2000. Melanization of Cryptococcus neoformans in human brain tissue. Lancet 355: 2049-2050.

Odom, A., Muir, S., Lim, E., Toffaletti, D.L., Perfect, J., and Heitman, J. 1997. Calcineurin is required for virulence of Cryptococcus neoformans. EMBO J. 16: 2576-2589.

Perfect, J.R., Wong, B., Chang, Y., Kwon-Chung, K.J., and Williamson, P.R. 1998. Cryptococcus neoformans: Virulence and host defenses. Med. Mycol. 36: 79-86.

Salas, S.D., Bennett, J.E., Kwon-Chung, K.J., Perfect, J.R., and Williamson, P.R. 1996. Effect of the laccase gene, CNLAC1, on virulence of Cryptococcus neoformans. J. Exp. Med. 184: 377-386.

Sambrook, J., Fritsch., E.F., and Maniatis, T. 1989. Molecular cloning: A laboratory manual, 2nd ed. Cold Spring Harbor Laboratory Press, Cold Spring Harbor, NY.

Schein, J.E., Tangen, K.L., Chiu, R., Shin, H., Lengeler, K.B., MacDonald, W.K., Bosdet, I., Heitman, J., Jones, S.J.M., Marra, M.A., et al. 2002. Physical maps for genome analysis of serotype A and D strains of the fungal pathogen Cryptococcus neoformans. Genome Res. 12: 1445-1453.

Schwelnus, W., Richert, K., Opitz, F., Gross, T., Habara, Y., Tani, T., and Kaufer, N.F. 2001. Fission yeast Prp4p kinase regulates pre-mRNA splicing by phosphorylating a non-SR-splicing factor. EMBO Rep.. 2: 35-41.

Sia, R.A., Lengeler, K.B., and Heitman, J. 2000. Diploid strains of the pathogenic basidiomycete Cryptococcus neoformans are thermally dimorphic. Fungal Genet. Biol. 29: 153-163.

Smoot, L.M., Smoot, J.C., Graham, M.R., Somerville, G.A., Sturdevant, D.E., Lux Migliaccio, C.A., Sylva, G.L., and Musser, J.C. 2001. Global differential gene expression in response to growth temperature alteration in group A Streptococcus. Proc. Natl. Acad. Sci. 98: 10416-10421.

Sokal, R.R., and Rohlf, F.J. 1981. Biometry. W.H. Freeman, New York, NY.

Soll, D.R. 1997. Gene regulation during high-frequency switching in Candida albicans. Microbiology 143: 279-288.

Steels, E.L., Learmonth, R.P., and Watson, K. 1994. Stress tolerance and membrane lipid unsaturation in Saccaromyces cerevisiae grown aerobically or anaerobically. Microbiology 140: 569-576. 
Steen et al.

Storlazzi, A., Maresca, B., and Gargano, S. 1999. cAMP is involved in transcriptional regulation of $\Delta 9$-desaturase during Histoplasma capsulatum morphogenesis. Mol. Cell Biol. Res. Commun. 2: $172-177$.

Velculescu, V.E., Zhang, L., Vogelstein, B., and Kinzler, K.W. 1995. Serial analysis of gene expression. Science 270: 484-487.

Velculescu, V.E., Zhang, L., Zhou, W., Vogelstein, J., Basrai, M.A., Bassett, Jr., D.E., Hieter, P., Vogelstein, B., and Kinzler, K.W. 1997. Characterization of the yeast transcriptome. Cell 88: $243-251$.

Vincent, V.L. and Klig, L.S. 1995. Unusual effect of myo-inositol on phospholipid biosynthesis in Cryptococcus neoformans. Microbiology 141: 1829-1837.

Wang, Y., Aisen, P., and Casadevall, A. 1995. Cryptococcus neoformans melanin and virulence: Mechanism of action. Infect. Immun. 63: $3131-3136$.

Wang, P., Cardenas, M.E., Cox, G.M., Perfect, J.R., and Heitman, J. 2001. Two cyclophilin A homologs with shared and distinct functions important for growth and virulence of Cryptococcus neoformans. EMBO Rep. 2: 511-518.

Wickes, B.L., Mayorga, M.E., Edman, U., and Edman, J.C. 1996. Dimorphism and haploid fruiting in Cryptococcus neoformans: Association with the $\alpha$-mating type. Proc. Natl. Acad. Sci. 93: 7327-7331.

Wu, J., Suka, N., Carlson, M., and Grunstein, M. 2001. TUP1 utilizes histone H3/H2B-specific HDA1 deacetylase to repress gene activity in yeast. Mol. Cell 7: 117-126.

Wyrick, J.J., Holstege, F.C.P., Jennings, E.G., Causton, H.C., Shore, D., Grunstein, M., Lander, E.S., and Young, R.A. 1999.
Chromosomal landscape of nucleosome-dependent gene expression and silencing in yeast. Nature 402: 418-421.

Zhang, L., Zhou, W., Velculescu, V.E., Kern, S.E., Hruban, R.H., Hamilton, S.R., Vogelstein, B., and Kinzler, K.W. 1997. Gene expression profiles in normal and cancer cells. Science 276: 1268-1272.

\section{WEB SITE REFERENCES}

http://cgt.genetics.duke.edu/data/index.html; genomic shotgun sequence data, Duke University Center for Genome Technology.

http://mgm.duke.edu; Duke University Department of Molecular Genetics \& Microbiology

http://www.genome.ou.edu/cneo.html; EST databases for strains JEC21 and H99, University of Oklahoma's Advanced Center for Genome Technology.

http://www.ncbi.nlm.nih.gov; National Center for Biotechnology Information

http://www.sagenet.org; protocol for performing serial analysis of gene expression (SAGE).

http://www-sequence.stanford.edu; Shotgun sequence data from the C. neoformans Genome Project (assemblies 010512 and 011005), Stanford Genome Technology Center.

http://www.tigr.org/tdb/edb2/crypt/htmls/index.shtml; The Institute for Genomic Research.

Received January 11, 2002; accepted in revised form May 23, 2002.

1400 Genome Research 


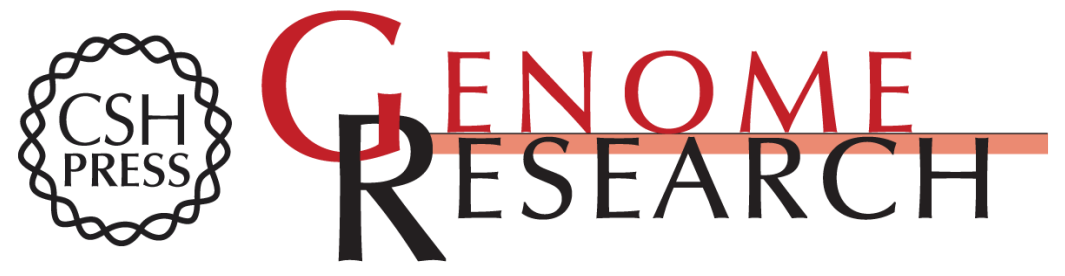

\section{Temperature-Regulated Transcription in the Pathogenic Fungus Cryptococcus neoformans}

Barbara R. Steen, Tian Lian, Scott Zuyderduyn, et al.

Genome Res. 2002 12: 1386-1400

Access the most recent version at doi:10.1101/gr.80202

References This article cites 56 articles, 32 of which can be accessed free at:

http://genome.cshlp.org/content/12/9/1386.full.html\#ref-list-1

\section{License}

Email Alerting Receive free email alerts when new articles cite this article - sign up in the box at the Service top right corner of the article or click here.

\section{Affordable, Accurate Sequencing.}

To subscribe to Genome Research go to: https://genome.cshlp.org/subscriptions 